\title{
Review
}

\section{Structure-Function Relationships of Nuclear Lamins}

\author{
Shalaka Patil and Kundan Sengupta * \\ Biology, Indian Institute of Science Education and Research (IISER), Pune 411008, India; \\ shalaka.patil@students.iiserpune.ac.in \\ * Correspondence: kunsen@iiserpune.ac.in; Tel.: +91-20-25908071
}

\begin{abstract}
Nuclear lamins are type $\mathrm{V}$ intermediate filament proteins that form a filamentous meshwork beneath the inner nuclear membrane. Additionally, a sub-population of A-type and Btype lamins is localized in the nuclear interior. The nuclear lamina protects the nucleus from mechanical stress and mediates nucleo-cytoskeletal coupling. Lamins form a scaffold that partially tethers chromatin at the nuclear envelope. The nuclear lamina also stabilizes protein-protein interactions involved in gene regulation and DNA repair. The lamin-based protein sub-complexes are implicated in both nuclear and cytoskeletal organization, the mechanical stability of the nucleus, genome organization, transcriptional regulation, genome stability, and cellular differentiation. Here we review recent research in the field of nuclear lamins and their role in modulating various nuclear processes and their impact on cell function.
\end{abstract}

Keywords: Nucleus, Nuclear envelope, Lamins, Genome organization, Chromatin, Gene expression.

\section{Introduction}

Spatial genome organization and subnuclear compartmentalization are essential for the maintenance of normal cellular physiology. One of the critical subnuclear structures is the nuclear lamina; which along with the nuclear membrane forms a barrier that protects the nucleus and the genome [1]. The nuclear lamina is a protein meshwork at the nuclear envelope of $\sim 15-20 \mathrm{~nm}$ thickness in mammalian cells [2]. Lamins contribute to the integrity of the nuclear envelope in various cell types $[3,4]$. Nuclear lamins belong to the type $\mathrm{V}$ intermediate filament family of proteins, which has complex roles in the maintenance of normal cellular physiology [5,6]. A large number of nuclear proteins are associated with nuclear lamins and are implicated in modulating various cellular processes and tissue-specific cell functions $[7,8]$. There is growing evidence suggesting the role of nuclear lamins in a wide range of structural processes such as maintaining mechanical stability of the nucleus, nuclear and cytoskeletal organization, chromatin organization, nuclear assembly/disassembly as well as cellular processes such as transcription, replication, DNA damage repair, genome stability, differentiation and senescence [5,9-12]. Lamins provide binding sites for regulatory proteins such as $\mathrm{pRb}$ and c-fos, among others $[9,13]$. Furthermore, lamins are involved in the coupling of the nucleus with the cytoskeleton, the destabilization of which severely impacts the cytoskeletal organization, and the position of the nucleus within cells [14,15]. The broad spectrum of diseases caused by mutations or altered expression of lamins, namely laminopathies provide crucial insights into the structure-function relationships of lamins across mammalian cells [16]. Research in the past two decades demonstrates that lamins are not only the structural components of the nucleus but are also involved in the maintenance of nuclear architecture, facilitate cell signalling and perform regulatory roles at the nuclear envelope.

\section{Physical properties of Nuclear Lamins}

Lamins are evolutionarily conserved and belong to the intermediate filament (IF) superfamily, and are classified as type $\mathrm{V}$ intermediate filament proteins $[17,18]$. Lamins are structural proteins of the nuclear envelope that are unique to metazoans. Like all intermediate filament proteins, lamin monomers have a tripartite structural organization consisting of a short globular N-terminal (head) 
domain followed by a central $\alpha$-helical coiled-coil (rod) domain and a globular C-terminal (tail) domain (Figure 1A) [2,19]. Unlike cytoplasmic IF proteins, the tail domain of lamins harbors laminspecific motifs; a nuclear localization signal (NLS), an immunoglobulin (IgG) fold motif, and a Cterminal -CAAX (C, cysteine; A, aliphatic amino acid; X, any amino acid) motif (Figure 1A) [19]. NLS is essential for directing lamins into the nucleus, where they assemble into the nuclear lamina; a fibrous proteinaceous meshwork beneath the inner nuclear membrane (INM) [2]. The -CAAX motif is a site of extensive post-translational modifications involving sequential farnesylation (at the cysteine residue), proteolysis, and carboxymethylation of the -AAX sequence [20,21].

Figure 1

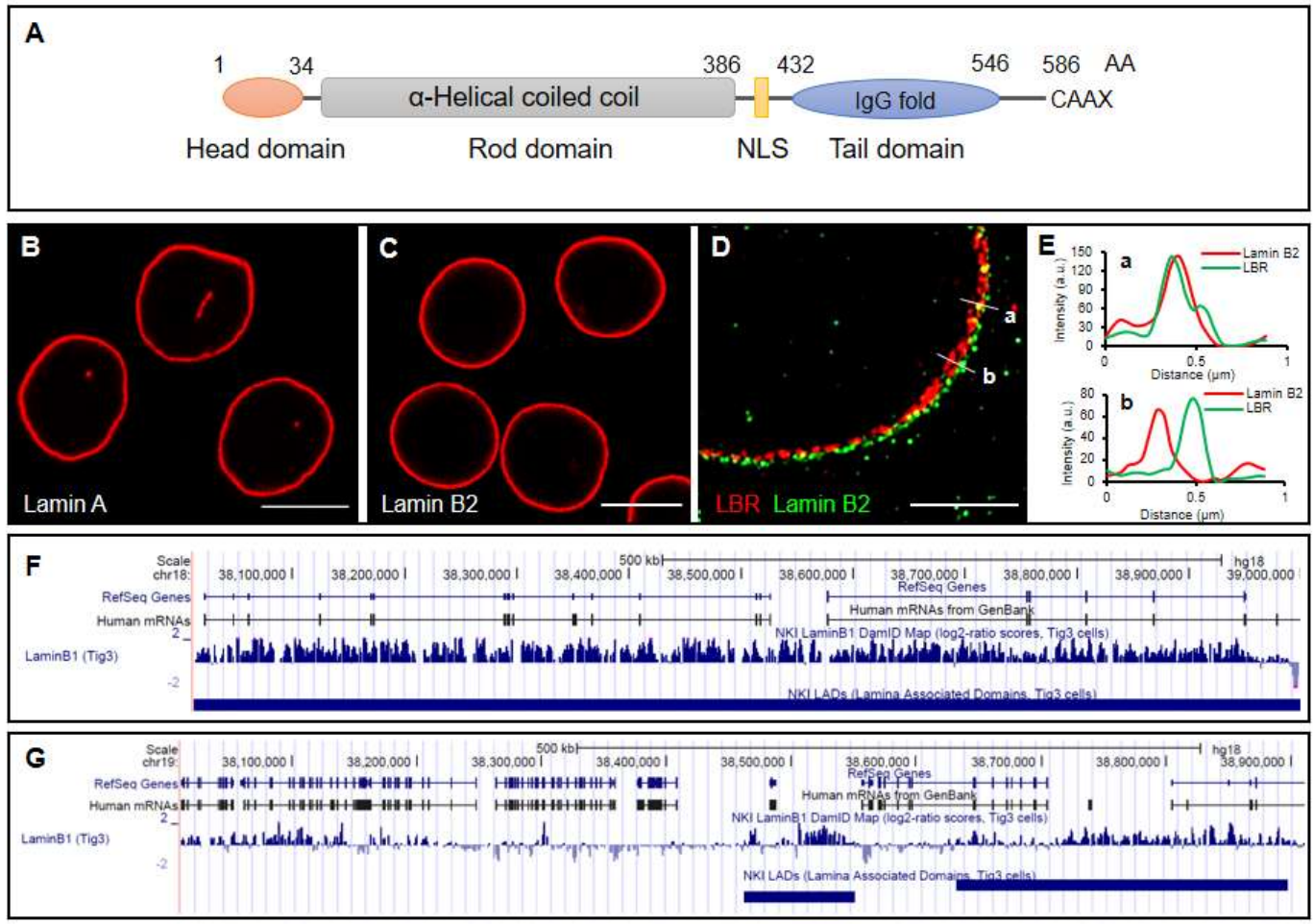

Figure 1: Structure, localization, and chromatin binding of nuclear lamins (A) The domain organization of a lamin monomer showing the $\mathrm{N}$-terminal head domain, central rod domain, and the C-terminal tail domain which includes nuclear localization signal (NLS), IgG fold, and -CAAX motif. Schematic represents amino acid positions for lamin B1 protein. (B) and (C) Confocal microscopy images of colorectal cancer cells (HCT116) immunostained with Lamin A and Lamin B2 respectively, Scale bar $10 \mu \mathrm{m}$. (D) Structured Illumination Microscopy (SIM) image of colorectal cancer cells (SW480), co-immunostained with Lamin B2 (green) and LBR (red). Scale bar $\sim 3 \mu \mathrm{m}$. (E) Line scan profiles across the nuclear envelope in D representing Lamin B2 and LBR showing (a) overlapping and (b) non-overlapping regions. (F) and (G) UCSC Genome Browser view of LADs identified by lamin B1 DamID-seq in a region of (F) chr18q12.3 and (G) chr19q13.11 (Source: [183]). Note that human gene-poor chromosome 18 shows higher lamina associations as compared to gene-rich chromosome 19.

Lamins are of two major subtypes: A-type and B-type lamins. In mammals, A-type lamins are encoded by a single gene $L M N A$, which upon alternate splicing, result in lamin A, and lamin C - both of which are found in terminally differentiated somatic cells. LMNA also generates the less abundant somatic lamin $\mathrm{A} \Delta 10$ and germ cell lamin $\mathrm{C} 2$ isoforms [22]. The B-type lamins, which are expressed in all cell types, are encoded by two different genes. $L M N B 1$ encodes for lamin B1 protein, whereas LMNB2 encodes for somatic lamin B2, and lamin B3 is specific to male germ cells [23]. B-type lamins are tightly associated with the nuclear envelope and the inner nuclear membrane by virtue of a permanently farnesylated and carboxy-methylated CAAX motif [21]. Mature lamin A and lamin C are generated from enzymatic cleavage of $C$-terminal amino acids of pre-lamin $A$, that includes the - 
CAAX motif, due to which A-type lamins are more soluble during mitosis and interphase stages of the cell cycle [20].

Lamins form coiled-coil parallel dimers that assemble into higher-order filamentous structures similar to other intermediate filament proteins, such as keratin and vimentin [24,25]. The detailed structure of the nuclear lamina has been challenging to elucidate, owing to its refractory nature. Electron microscopy (EM) studies on purified mammalian and avian lamins revealed that these proteins associate to form $\sim 50 \mathrm{~nm}$ rod-shaped homodimers, which spontaneously assemble in vitro into intermediate-like filaments [24,26]. 3D Structured Illumination Microscopy (3D-SIM) and cryoElectron Tomography (cryo-ET) studies of the lamina meshwork revealed that different lamin isoforms assemble into distinct yet interlinked filamentous networks with unique properties of assembly to build up the nuclear lamina $[27,28]$. A-type and B-type lamins assemble into head-to-tail polymers of tetrameric filaments of $\sim 3.5 \mathrm{~nm}$ thickness. These filaments are arranged in a partially staggered conformation wherein, the immunoglobulin (IgG) domain repeats every $20 \mathrm{~nm}$ alongside the lamin filament [27]. Stochastic Optical Reconstruction Microscopy (STORM) visualization of the nuclear lamina in mammalian cells reveals that lamin B1 and lamin $\mathrm{A} / \mathrm{C}$ form overlapping concentric networks; wherein lamin $B 1$ shows curvature dependent localization in the outer concentric ring and restrains the outward protrusions of the lamin A/C network [29,30]. The organization of the nuclear lamina is complex and cell-type specific.

Furthermore, lamins also exist in the nucleoplasm with functions that are novel and distinct from that of the nuclear envelope [9,31]. A sub-population of A-type lamins upon phosphorylation (Ser22, Ser390, Ser392), dissociate from the nuclear lamina during interphase, and redistribute throughout the nucleoplasm; whereas B-type lamins are largely membrane-associated throughout the cell cycle (Figure 1B and 1C) [32,33]. Lamin phosphorylation and other post-translational modifications complement lamin function in terms of the stability of the lamina, lamin-protein interactions, chromatin binding, and gene regulation. Fluorescence Correlation Spectroscopy (FCS) performed on fluorescently tagged lamins revealed that nucleoplasmic lamin complexes are considerably more mobile than the lamins associated with the nuclear envelope [34]. The relative stoichiometry of A-type and B-type lamins is often cell-type specific and exists in a dynamic equilibrium [35]. Additionally, the ratio of A:B-type lamins modulates tissue-specific gene expression and determines mechanical properties of the nucleus $[35,36]$.

\section{Interacting partners of Nuclear Lamins}

Lamins interact with various proteins both at the INM and nucleoplasm (Figure 2). Among the first identified mammalian lamin-binding proteins are: lamina-associated polypeptide 1 (LAP1) and the LEM domain-containing proteins (LAP2, emerin, MAN1) in the INM [37,38]. The bi-helical LEM domain interacts with an evolutionarily conserved DNA-associated protein termed Barrier to Autointegration Factor (BAF) [39,40]. Lamins and LEM proteins in the INM together anchor heterochromatin to the nuclear lamina by associating with BAF and via direct interaction with DNA (Figure 2) [41,42]. Another lamin interacting INM protein is the Lamin B Receptor (LBR) - composed of eight transmembrane domains and a sterol reductase activity (Figure 1D and 1E) [43]. The chromatin binding domain of LBR associates with and tethers chromatin closer to the nuclear envelope. Further, LBR recognizes the histone modification - H4K20Me2 (histone-4 lysine-20 dimethylation) and is involved in the compaction of associated chromatin by the recruitment of $\mathrm{HP} 1 \alpha, \mathrm{MeCP} 2$, and B-type lamins collectively involved in transcriptional silencing [44,45]. Loss of both Lamin A/C and LBR in rod cells of mouse retina showed an inverted nuclear architecture with heterochromatin localized towards the nuclear interior, while euchromatin was closer to the nuclear envelope [46]. Lamins interact with nuclear envelope transmembrane proteins (NETs) in a tissuespecific manner $[47,48]$. The differences in the composition of nuclear lamina and stoichiometry of A- 
type and B-type lamins potentially manifest cell-type-specific differences in binding partners for lamins. Lamin interactomes define tissue-specific functions of nuclear lamins.

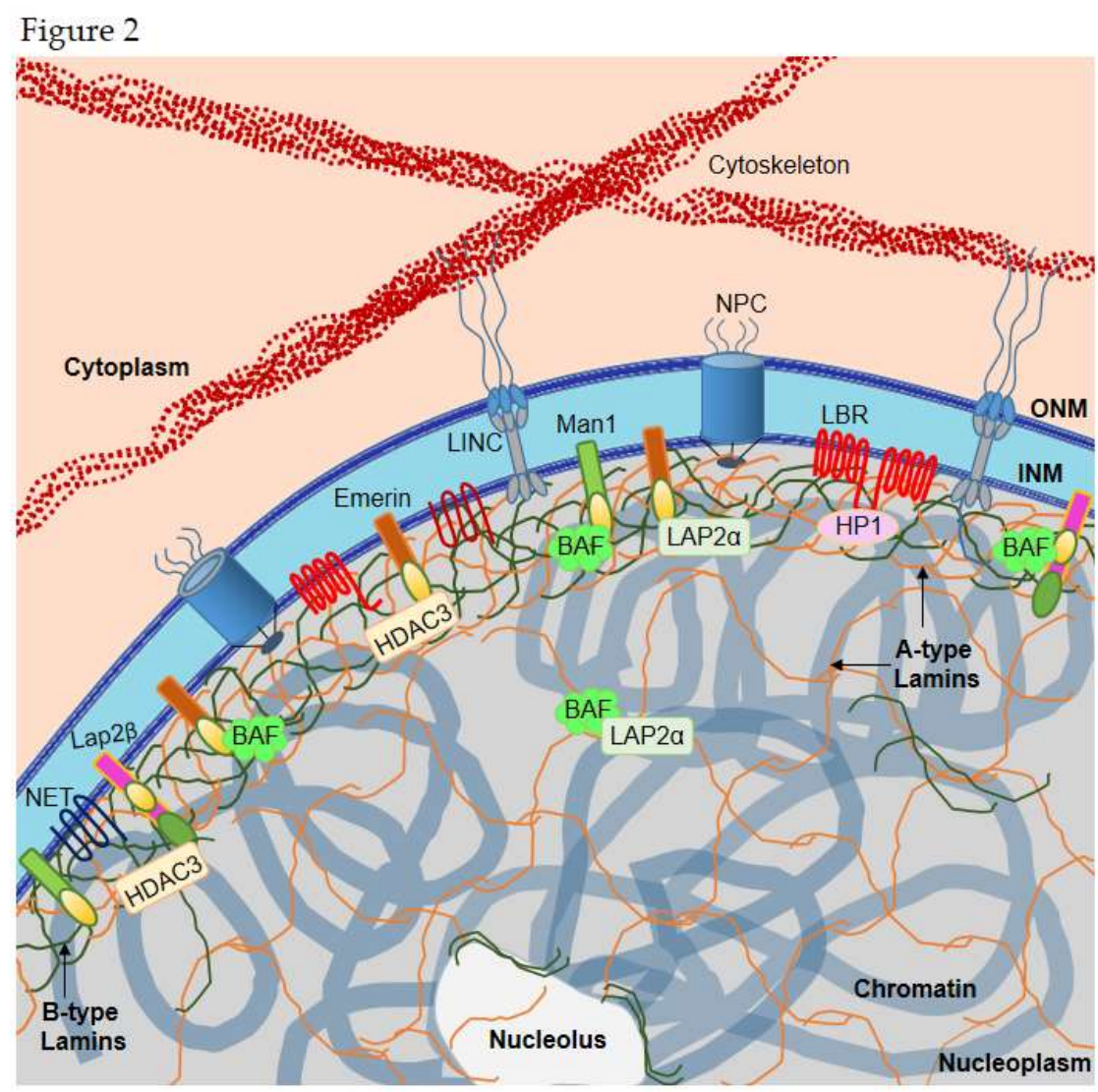

Figure 2: Organization of the nuclear envelope The nuclear envelope (NE) is composed of the outer nuclear membrane (ONM), inner nuclear membrane (INM), nuclear lamina, nuclear pore complex (NPC), and nuclear envelope transmembrane proteins (NET). A-type lamins and B-type lamins together form a filamentous meshwork of nuclear lamina at the NE and are also localized in the nucleoplasm. The linker of nucleoskeleton and cytoskeleton (LINC) complex connects the nucleus to the cytoskeleton. This schematic shows a subset of INM proteins interacting with the nuclear lamina such as LEM domain NETs (Lap2 $\beta$, Emerin, Man1), Lamin B Receptor (LBR) and their chromatin interacting partners such as barrier to autointegration factor (BAF), histone deacetylase 3 (HDAC3) and heterochromatin protein 1 (HP1). The nuclear lamina and associated proteins modulate the spatial organization of chromatin, heterochromatinization, gene expression, nuclear stability, and mechanotransduction.

The LINC (linker of nucleoskeleton and cytoskeleton) protein complex couples the nuclear lamina to the components of the cytoskeleton (Figure 2), composed of SUN domain proteins in the INM and KASH domain proteins in the outer nuclear membrane (ONM) [49]. The nucleoplasmic domain of the SUN protein interacts with lamins, whereas its transluminal domain interacts with the KASH domain proteins [50]. LINC complex mediates interactions between nuclear lamins and chromatin with various components in the cytoplasm such as actin filaments, microtubules, centrosomes, and cytoplasmic organelles [14,51,52].

Filamentous networks of A-type and B-type lamins provide attachment sites for nuclear pore complexes (NPCs) and regulate the symmetric distribution of NPCs; however, lamin C shows preferential association with the NPC over lamin A [53,54]. Lamins, along with NETs and NPCs interact with DNA, histones, chromatin organizer proteins, epigenetic chromatin marks, and transcriptional regulators $[11,55,56]$. These interactions largely influence chromatin organization and function. Lamin-binding proteins contribute to nuclear architecture, mechanics, and signalling $[57,58]$. The difference in the composition of lamin-interacting proteins in different tissues can 
potentially modulate tissue-specific lamin functions [47]. In summary, the lamin meshwork emerges as a complex network of interactions at the nuclear envelope, further modulated by cell- and tissuespecific functions.

\section{Lamins maintain integrity of the nucleus}

Lamins are the major structural components that contribute to the shape, rigidity, and mechanical integrity of the nucleus [36,59]. Nuclear morphology is strikingly altered upon lamin depletion in C. elegans, D. melanogaster, Lamin A/C knockout mice, and Lamin B1 knockdown HeLa cells [60-62]. Loss of lamins is frequently associated with nuclear blebs, invaginations, and transient ruptures of the nuclear envelope [63]. Nuclear stiffness increases with the ratio of A:B-type lamins [35]. Lamin A/C deficient human fibroblasts have relatively fragile nuclei that are more deformable under mechanical strain and exhibit altered mechanotransduction [62,64,65]. Lamin A/C and lamin B1 both contribute to nuclear stiffness; wherein B-type lamins impart elastic properties to the nuclear envelope and nuclear viscosity is specified by lamin A/C [66-68]. These differences in the function of A-type and B-type lamins are due to the ability of A-type lamins to form a thicker meshwork ( 15 $\mathrm{nm})$ than B-type lamins $(\sim 7 \mathrm{~nm})$ [69]. Additionally, the relative stoichiometry of A-type and B-type lamins determines mechanical stiffness of the nucleus [36].

Lamin depletion alters nucleo-cytoskeletal coupling, as lamin deficient cells induce a separation of the microtubule-organizing center from the nuclear envelope, impairing centrosome positioning [15]. Moreover, mouse fibroblasts deficient in A-type lamins show altered cytoskeletal organization and reduced cytoplasmic stiffness [15,70]. Interestingly, during cell migration through narrow constrictions, the nuclear envelope was ruptured at the leading edge of cells, facilitated by reduced lamin levels [36,71]. B-type lamins are essential for the forward movement of the nucleus during neuronal migration; further, lamin B1 deficient neurons showed nuclear rupture accompanied by DNA damage and cell death [72,73].

Lamin pools within the nucleoplasm contribute to normal cellular processes by associating with various nuclear and nucleolar structures [74]. Lamin A/C associates with nuclear components such as the nuclear pore complex and promyelocytic leukemia nuclear (PML) bodies [75,76]. Lamin A is required for the compartmentalization of PML bodies, which also accumulate within nuclear blebs and the nuclear envelope in lamin A-deficient cells [77]. While lamin B2 is enriched as punctae at the granular component (GC) of the nucleolus in colorectal cancer cells, lamin A is localized in the nucleolar interior [78]. Interestingly, lamin B2 showed a separation of function at the nuclear envelope and nucleolus of colorectal cancer cells. The $\mathrm{N}$-terminal head domain of lamin B2 maintains discrete, spherical nucleolar morphology; while, a stretch of seven amino acids (SLSATGR) in the Cterminal tail domain of lamin B2 is essential for bleb-free morphology of the nucleus [78]. Membraneassociated fractions of B-type lamins also contribute to nuclear envelope assembly and chromosome organization post-mitosis [79]. Needless to mention, the development of new imaging and molecular approaches is essential for unravelling the structure and function of nucleoplasmic lamins.

\section{Lamins modulate chromatin organization}

The genome is non-randomly organized as chromosome territories that occupy a distinct subvolume and non-random spatial positions in the interphase nucleus [80,81]. Chromatin at the nuclear periphery associates with the nuclear lamina through lamina associated domains (LADs), characterized by the presence of lamina associated sequences (LASs) (Figure 1F) [82,83]. The association of chromosomes with the lamina is largely dependent on DNA sequences and shows a greater propensity to associate with repetitive sequences typically enriched, for instance, in genepoor chromosome 18 as compared to gene-rich chromosome 19 (Figure 1F and 1G). Interactions of the genome with the nuclear lamina are dynamic and modulated across developmental stages [8486]. For example, during adipogenic differentiation, a large number of lamin-genome associations are remodeled globally that alters associated transcriptional outputs [87]. Lamins directly interact with DNA, chromatin, and histones in vitro, and are required for chromatin organization in vivo [44,88,89]; since depletion of mammalian lamin B1 and lamin A/C, or lamin in C. elegans shows 
chromatin reorganization and alters chromatin dynamics [90]. In human fibroblasts, for instance, $\sim 40 \%$ of the genome comprises LADs that range from $\sim 10 \mathrm{~kb}$ to $\sim 10 \mathrm{Mb}$ in size and this region is enriched for (i) heterochromatin marks (ii) gene-poor chromatin (iii) low transcriptional activity and (iv) late replication timing [82,91]. Borders of LADs are enriched in H3K9Me2/3 (histone 3 lysine 9 ditrimethylation), H3K27Me3 (histone 3 lysine 27 trimethylation) and are flanked by the insulator and genome organizer - CTCF (CCCTC binding factor) [83,84]. LADs show higher enrichment on intergenic regions, and silent or weakly expressed genes in mammals, nematodes, and fruit flies $[85,92]$.

Chromatin-association of the nuclear lamina is mediated by protein complexes formed between lamins and lamin-binding proteins at the INM, via direct chromatin-binding or the recruitment of intermediate factors $[93,94]$. Studies on mammalian cells and D. melanogaster have demonstrated that heterochromatin is tethered to the nuclear lamina by lamins and lamin-interacting NET proteins via their mediators - HP1a, BAF, PRR14 or repressive histone marks such as H3K9Me2/3, H3K27Me2/3, and H4K20Me2 [82,92]. Lamins significantly contribute to the maintenance of LADs, however, these interactions are stabilized by lamin interactors at the nuclear interior (Lamin A/C with LAP2 $\alpha, \mathrm{BAF}$ ) and nuclear envelope (Lamin A/C with Emerin, SUN1, SUN2, Nesprin-1 $\alpha$, Nesprin-2 and B-type Lamins with LBR, LAP2 $\beta, \mathrm{HP} 1 \alpha$ ) respectively [9,95-97]. LADs bound by B-type lamins are proximal to the nuclear envelope encompassing heterochromatin, while those bound by A-type lamins exist both at the nuclear envelope and nuclear interior, involving heterochromatin and euchromatin respectively $[95,98]$. LADs at the nuclear envelope are more compact also due to their proximity to the lamin meshwork, which hinders chromatin mobility [11]. Spatial organization of LADs in the nucleus is an important factor in the functional compartmentalization of the genome.

A comparison of LADs from different cell lineages derived from mouse embryonic stem cells (mESCs) showed that LADs are of two types; (a) facultative LADs (fLADs) and (b) constitutive LADs (cLADs) [83]. Lamin-B1 derived DamID readouts in different cell lineages showed that cLADs were consistently associated with the nuclear lamina, whereas fLADs were detached from the lamina in a cell-type-specific manner [99,100]. This suggests altered localization and function of cLADs and fLADs, depending on their genomic features in the interphase nucleus [94,101,102]. The fLADs are associated with differentiation, as they harbor cell-type-specific genes that are released from lamins for the activation of tissue-specific gene expression upon lineage commitment $[103,104]$. For example, during Jurkat T-cell activation, genomic loci (CBLP and IL2) and enhancers specific to T-cell function are released from the nuclear lamina, but are constrained in an active compartment proximal to the lamina [99]. The binding of A-type lamins to LADs is altered during adipogenic differentiation in response to metabolically regulated O-GlcNAcylation of histone $\mathrm{H} 2 \mathrm{~B}$, thereby contributing to differentiation-specific repression of genes [105].

The aberrant splicing of the LMNA gene is associated with Hutchinson-Gilford Progeria Syndrome (HGPS), which shows striking changes in chromatin architecture [20,106]. Imaging HGPS fibroblasts reveals the loss of heterochromatin tethering to the nuclear lamina [106,107]. Depletion of B-type lamin in S2 cells of D. melanogaster showed a repositioning of the testis-specific gene cluster (60D1 locus) toward the nuclear interior and impaired the segregation of chromatin into active and inactive compartments [108,109]. Moreover, lamin depletion alters the spatial positions of chromosome territories in mammalian cell lines [97,110]. For instance, CT18 was repositioned away from the nuclear envelope in lamin B1 knockout murine cells [111], whereas fibroblasts derived from laminopathies showed a mislocalization of the gene-poor CT13 and CT18 respectively away from the nuclear envelope [112]. Lamins, with emerin, nuclear actin, and myosin constitute intra-nuclear complexes that are involved in the spatial localization of gene-rich chromosome territories as well as individual gene loci in the interphase nucleus [113-115]. Additionally, co-depletion of lamin A/C and emerin showed altered sub-cellular localization of NM1 (nuclear myosin-1), chromosome territory positions and enhanced chromatin mobility in colorectal cancer cells [115]. However, how the relative stoichiometry of A-type and B-type lamins, and its cell-cell variability impacts chromosome territory positions and LAD organization in a tissue-specific manner remains unclear. 


\section{Lamins modulate gene expression}

The nuclear envelope is largely a transcriptionally repressive region. However, certain regions are nevertheless transcriptionally permissive [116]. This is consistent with the finding that anchoring genes to the nuclear lamina correlates with tissue-specific gene repression, and this tethering mechanism is vital for stable repression of genes during differentiation [102,117,118]. For example, in neuronal progenitor cells of $D$. melanogaster, tethering of the hunchback $(\mathrm{hb})$ gene to the nuclear lamina is required for its stable repression [119]. Nuclear lamins are implicated in regulating transcriptional activity by modulating chromatin structure and organization at the nuclear periphery $[120,121]$. Overexpression of Lamin A/C shows a reduction in RNA polymerase II-mediated transcription and disrupts the spatial organization of RNA polymerase II speckles in the interphase nucleus [122]. Furthermore, lamins function as a scaffold for RNA polymerase II and associated transcription factors [34,122]. Activation of tissue-specific gene transcription during cell differentiation is frequently associated with the movement of gene loci away from the nuclear lamina to the nuclear interior, at sites that are enriched for transcription factors [123,124]. For instance, the immunoglobulin heavy chain $(\mathrm{IgH})$ locus, repositions away from the nuclear envelope during B-cell development [123].

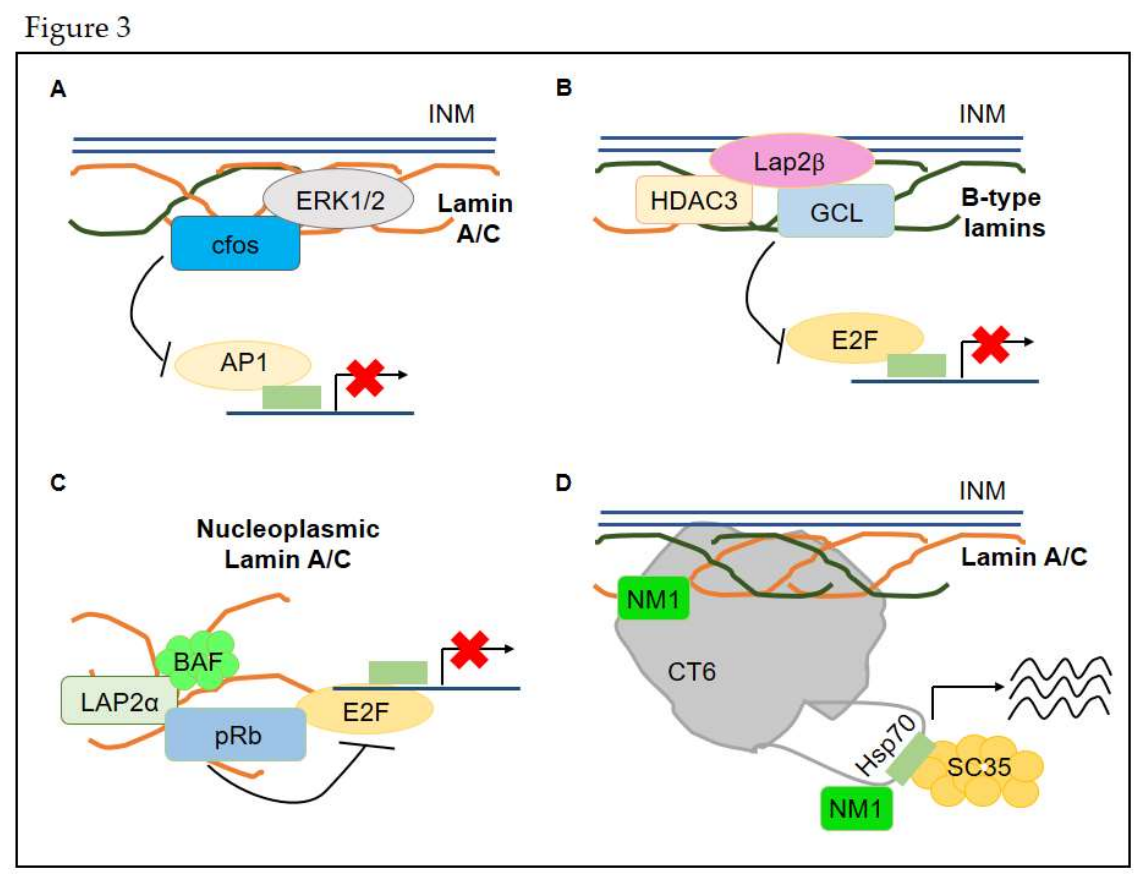

Figure 3: Mechanisms of lamin mediated gene regulation (A) The c-Fos protein is associated with the nuclear envelope through interaction with A-type lamins in serum-deprived conditions. AP-1 responsive genes are OFF under these conditions. Lamin A bound ERK1/2 functions as a molecular switch for the mitogen dependent activation of AP-1 by releasing c-Fos from the lamina. (B) Transcriptional repressor germ-cell-less (GCL) is localized at the nuclear envelope by associating with B-type lamins and LAP2 $\beta$. This interaction reduces the transcriptional activity of E2F. (C) Interaction of $\mathrm{pRb}$ with lamin A/C and LAP2 $\alpha$ anchors the pRb/E2F complex in the nucleoplasm, reducing the pool of available E2F, arresting cell cycle at the G1 pRb-dependent checkpoint. (D) A novel regulatory role for lamin A/C and nuclear myosin (NM1) in the modulation of the heat shock response. The Hsp70 gene locus moves away from the nuclear envelope and shows enhanced contact with SC35 nuclear speckles upon heat shock, which enhances its gene expression levels.

Nuclear lamins interact with various transcription factors that affect cell proliferation, differentiation, and apoptosis (Figure 3) [125]. A-type lamins interact with transcription factors such as pRb, c-Fos, AP-1, SREBP1, ERK1/2, MEL18, and GCL [126]. Many of the transcription factors bound 
by lamin $\mathrm{A}$ are sequestered at the nuclear envelope in inactive complexes $[127,128]$. These factors are released from the lamin anchor upon specific signalling cues leading to the activation of target genes. For instance, the transcription factor c-Fos is sequestered at the nuclear envelope by A-type lamins and released during mitogen-activated protein kinase (MAPK) signalling to facilitate cell proliferation (Figure 3A) [129]. A-type lamins function as transcriptional repressors when targeted to promoters [130]. Robust transcriptional repression of promoters with Gal4 binding sites was observed upon expressing human lamin A as a fusion protein to the Gal4 DNA-binding domain in yeast and cultured human cells $[130,131]$. Promoters of transcriptionally active genes positioned at the nuclear envelope are often excluded from the nuclear lamina-association, further reiterating the significance of promoter-lamina interactions in gene repression [132]. The B-type lamins are involved in transcriptional repression through their interacting partner LAP2 $\beta$ at the INM, which shows a direct interaction with the transcription regulator (GCL) and epigenetic modifier (HDAC3) (Figure 3B) [126]. B-type lamins regulate Oct-1 dependent genes; since the disruption of the interaction between lamin B1 and Oct-1 resulted in the down-regulation of oxidative stress response genes and elevated reactive oxygen species levels [133].

Gene expression profiling of lamin A/C or lamin B2 depleted colorectal cancer cells showed transcriptional deregulation [97]. Additionally, a candidate gene locus ZNF570 repositioned away from the nuclear lamina in lamin B2 depleted cells, which correlated with a significant increase in its transcript levels [97]. Lamin C (LamC, D. melanogaster A-type lamin) and the transcription factor Hey partner to maintain nuclear architecture unique to differentiated enterocytes (ECs), as loss of Hey or aberrant lamin expression shows loss of EC identity [134]. Interestingly, transcriptionally active chromatin can also associate with lamin B1, forming dynamic euchromatin-lamin B1-associated domains in murine cells [135]. The depletion of lamin B1 from the euchromatin fraction massively alters the expression profile of EMT (epithelial to mesenchymal transition)-associated genes (CDH1, FN1, ZEB1 and TWIST2), thereby resulting in impaired EMT [135,136]. Furthermore, nuclear lamins also contribute to altered gene expression during heat shock [137]. Lamin A/C depletion prevented the translocation of Hsp70 (a key transcription factor driving the expression of heat shock-induced genes during heat shock) into the nucleus upon heat shock (Figure 3D). This uncovered a novel function for lamin $\mathrm{A} / \mathrm{C}$ in modulating gene expression and the nuclear localization of the genomic locus of Hsp70 upon heat shock [137].

\section{Lamins in mechano-signalling}

Nuclear lamina impacts gene expression by serving as a docking site for transcription factors and downstream signalling molecules [128]. Additionally, the nuclear lamina functions as a mechanosensor as it senses external mechanical signal, and functions as a mechanotransducer by relaying the signal that elicits appropriate cellular responses $[35,138]$. External mechanical stimulus results in the rearrangement of lamin filaments, which enables the transduction of external mechanical signals into the genome to elicit appropriate mechanosensitive transcriptional responses [139]. Lamina associated LEM domain-containing nuclear envelope proteins are implicated in the regulation of signalling at the nuclear periphery and mechanotransduction into the nucleus [42]. For instance, lamin-binding proteins regulate TGF- $\beta$-signaling in D. melanogaster, X. laevis, and mammals $[140,141]$. LEM protein - Man1, directly binds and inhibits R-SMAD, regulating BMP and TGF- $\beta$ signalling in early vertebrate development $[141,142]$. The lamin A, LAP $2 \alpha$, and pRb complex regulates nucleoplasmic anchoring of $\mathrm{pRb}$ and modulates E2F-dependent transcription in cell proliferation (Figure 3C) [8,143].

Phosphorylation of lamins regulates their solubility resulting in lamina assembly or disassembly, also as a response to external mechanical signals [144]. Lamins show enhanced phosphorylation and solubility in cells cultured on softer matrices [138]. This was consistent with enrichment in nucleoplasmic lamin levels in cells cultured on softer matrices. Remarkably, lamins were restored to the nuclear envelope in cells transferred from softer to stiffer substrates [145]. Taken together, lamins respond to external mechanical signals in a phosphorylation-dependent mechanism. Stem cells grown on substrates of differing elasticity showed differential lamin A levels, altering cell 
fate decisions [35,36]. For example, stiffer substrates promoted osteogenic differentiation of mesenchymal stem cells, while softer substrates promoted adipogenesis of the same cells [35].

A-type lamins show a greater diversity of function than B-type lamins. Lamin A impacts cellular growth and proliferation by participating in mitogen-activated protein kinase (MAPK)/extracellular signal-regulated kinase (ERK) pathway, wherein activated ERK1/2 interacts and co-localizes with Lamin A at the nuclear periphery (Figure 3A) $[129,146]$. Phosphorylated ERK1/2 activates c-Fos, which heterodimerizes with c-Jun to initiate transcription [129]. A-type lamins are also implicated in protein phosphatase 2A (PP2A) mediated inhibition of TGF- $\beta$ signalling [147]. Aberrant activation of TGF $\beta$ signalling hyperactivates the MAPK/ERK signalling pathway in a murine model for EDMD a disorder caused by a mutation in LMNA or EMD [148]. Additionally, lamin A tethers SKIP - a coactivator of Notch-dependent target genes, essential in the differentiation of mesenchymal stem cells [149]. Involvement of lamins in cell signalling highlights the ability of cells to utilize structural proteins as a signal processing unit by modulating lamin localization. This depends on posttranslational modifications of lamins, facilitating the integration of mechanical and architectural cues.

\section{Lamins and genome stability}

Genome instability is a hallmark of cancer. Cells encounter genomic instability typically due to defects in i) DNA damage repair pathways ii) DNA replication iii) chromosome segregation during mitosis $[150,151]$. Nuclear lamina proteins are implicated in various cellular processes that regulate genome stability, such as mitotic progression, cell cycle regulation, and nuclear assembly post-mitosis $[152,153]$. Disassembled components of nuclear lamina play a critical role in chromosome segregation that impact chromosome ploidy and post-mitotic nuclear assembly [154]. Additionally, a transient loss in the integrity of nuclear envelope during cell migration through confined spaces contributes to the genomic instability, as nuclear envelope rupture induces DNA double-strand breaks [155].

B-type Lamins are a part of the mitotic spindle matrix in X. laevis and mammalian cells [156]. Loss of lamin B2 perturbs chromosome segregation in colorectal cancer cells. Therefore, this function of lamin B2 is required to prevent chromosomal instability [157]. Furthermore, in HeLa cells, Lamin $\mathrm{A} / \mathrm{C}, \mathrm{LAP} 2 \alpha$ and BAF form a protein complex that localizes at the spindle and cell cortex during mitosis, for regulating mitotic spindle assembly and positioning [158]. Partial loss of lamin B1 expression in cancer cell lines resulted in delayed cell cycle and accumulation of cells in the early $S$ phase [159]. Interestingly, the maintenance of lamin B1 levels was essential for DNA replication and repair via regulation of the expression of key factors BRCA and RAD51 [159]. Another study showed that disruption of lamin $B 1$ led to nuclear blebbing and cytokinesis failure generating bi-nucleated and multinucleated cells $[111,136]$. Imaging GFP-histone 2B labelled in lamin A/C depleted ovarian epithelial cells followed by monitoring of narrow protrusions of nuclear materials, revealed that nuclear herniations break off from the main nucleus to form micronuclei, which were gradually degraded, leading to aneuploidy [160]. These observations emphasize the key role of lamins in maintaining the numerical stability of chromosomes.

Laminopathies caused by mutations in the LMNA gene are associated with genome instability with cells displaying high incidences of aneuploidy, DNA damage, and chromosome abnormalities $[107,161]$. Ectopic expression of lamin A mutant - progerin resulted in heterochromatin loss; further causing enhanced DNA replication defects, telomeric DNA damage, and impaired DNA damage response [107]. Lamins are also involved in DNA damage repair pathways, either to recruit factors involved in DNA repair or in epigenetically modulating the transcription of genes involved in DNA repair [162,163]. LMNA-null mouse fibroblasts show enhanced genomic instability, as observed by an increase in chromosome breaks, and $\gamma \mathrm{H} 2 \mathrm{AX}$ foci [162]. In summary, lamins are essential in regulating both structural and numerical stability of chromosomes. 3D-SIM has uncovered that $~ 50 \%$ of telomeres are associated with the nuclear lamina [164]. Interestingly, telomeres are stabilized by lamin-binding, and alterations in nuclear lamins lead to defects in telomere compartmentalization, homeostasis, and function, contributing to the genomic instability [165]. It is unclear if genomic rearrangements found in cancers and other developmental disorders, alter lamina-chromatin interactions and associated epigenetic regulatory pathways. 
10 of 20

\section{Nuclear lamins in cell proliferation and cancer}

Lamins function in both tumour-suppressive and oncogenic pathways and are also involved in the regulation of apoptosis [112]. Nucleoplasmic lamins in progeroid cells govern growth-regulating functions of LAP2 $\alpha$ to either enhance or inhibit cell proliferation, relative to the levels of A-type lamins in the nuclear interior [166]. Lamin B1 foci remain associated with major nuclear components such as chromatin, nucleoli, and nuclear speckles during mitosis [154]. These remnants of nuclear lamina potentially provide a structural memory that allows key features of nuclear architecture to be inherited from one cell cycle to the next [154]. B-type lamin levels are downregulated during physiological ageing in both humans and fruit flies [167,168]. However, oncogene-induced senescence is associated with the depletion of both A-type and B-type lamins, along with NETs (including LBR), which implies the disruption of heterochromatin tethers [169]. Furthermore, calcification of vascular smooth muscle cells was induced via activation of the senescence-associated secretory phenotype upon expression of pre-lamin A [170].

Nuclear envelope morphology is a biomarker of tumour grade and prognosis in cancer patients [171]. Recent studies have demonstrated the context-dependent role of nuclear lamins in human malignancies. Depletion of lamin A/C in a human lung cancer cell line elevated in vivo tumour growth rate in a xenograft model [172]. Conversely, independent knockdown of lamin A/C and lamin B1 in primary human diploid fibroblasts resulted in G1 arrest and premature senescence respectively, revealing cell-type-dependent effects of lamin levels on proliferation [143,173]. Nuclear lamins are downregulated in breast, colon, prostate, ovarian, gastric cancers, and are often associated with increased tumour aggressiveness and poor prognosis [174-178]. In contrast, colorectal and prostate tumours demonstrated an association between increased expression of lamin $\mathrm{A} / \mathrm{C}$ and disease progression $[179,180]$. Studies on B-cell activation revealed that lamin B1 acts as a negative epigenetic regulator of somatic hyper-mutation in normal B-cells and suppresses the aberrant mutations that drive lymphoid malignancy [181]. Lamin B2 is highly expressed in non-small cell lung cancer cells and promotes tumour proliferation and migration by silencing of E-cadherin via the upregulation of H3K9Me2 (dimethylation of histone-3 lysine-9) [182]. Taken together, the functions of lamins in cancer cells and the mechanisms that determine the profile of lamin expression during tumorigenesis strongly implicate nuclear lamins as biomarkers for the early detection and prognosis of cancers.

\section{Conclusion}

Lamin filaments play essential roles as structural elements in the maintenance of nuclear stability; however, lamin filaments and lamin oligomers both are involved in mechano-transduction in cells. The solubility of nuclear lamins, lamina meshwork, the localization and sequestration of lamin interactors are regulated by phosphorylation and other post-translational modifications. Nuclear lamins, together with lamina associated proteins are key modulators of heterochromatin organization, the spatial organization of the genome, gene expression, genome stability, and mechanosignalling. These functions are exhibited by dynamic association with the heterochromatin, euchromatin, and promoter sub-domains, thereby affecting chromatin accessibility and epigenetic regulatory pathways. Differences in the expression patterns and membrane-association properties of A-type and B-type lamins also suggest unique and non-overlapping roles of A-type and B-type lamins in the maintenance of nuclear structure-function relationships. 
Author Contributions: Conceptualization, S.P. and K.S.; writing-original draft preparation, S.P. and K.S.; writing-review and editing, S.P. and K.S.; visualization, S.P. and K.S.; supervision, K.S.; project administration, K.S.; funding acquisition, K.S. All authors have read and agreed to the published version of the manuscript.

Funding: This work was supported by a Wellcome Trust-DBT India Alliance Intermediate Fellowship (grant no. 500164/Z/09/Z), Department of Biotechnology, Ministry of Science and Technology (DBT, grant no. BT/PR13956/GET/119/22/2015), Department of Science and Technology (DST) Science and Engineering Research Board (SERB, grant no. EMR/2016/003983) and Intramural funding from Indian Institute of Science Education and Research (IISER), Pune. S.P. received senior research fellowship from UGC, New Delhi.

Acknowledgments: Authors are grateful to IISER-Pune for Microscopy facility and equipment support. We thank Dr. Roopali Pradhan and Maithilee Khot and Chromosome Biology Lab (CBL) members for their critical comments.

Conflicts of Interest: The authors declare no conflict of interest

\section{Abbreviations}

$\begin{array}{ll}\text { IF } & \text { Intermediate Filament } \\ \text { INM } & \text { Inner Nuclear Membrane } \\ \text { NET } & \text { Nuclear Envelope Transmembrane protein } \\ \text { NPC } & \text { Nuclear Pore Complex } \\ \text { LINC } & \text { LInker of Nucleoskeleton and Cytoskeleton } \\ \text { LBR } & \text { Lamin B Receptor } \\ \text { BAF } & \text { Barrier to Autointegration Factor } \\ \text { HP1 } & \text { Heterochromatin Protein 1 } \\ \text { LAP2 } & \text { Lamina Associated Polypeptide 2 } \\ \text { LAD } & \text { Lamina Associated Domain } \\ \text { CT } & \text { Chromosome Territory } \\ \text { DamID } & \text { DNA adenine methyltransferase IDentification }\end{array}$

\section{References}

1. Goldberg, M.; Harel, A.; Gruenbaum, Y. The nuclear lamina: molecular organization and interaction with chromatin. Crit. Rev. Eukaryot. Gene Expr. 1999, 9, 285-293, doi:10.1615/CritRevEukarGeneExpr.v9.i34.130 .

2. Aebi, U.; Cohn, J.; Buhle, L.; Gerace, L. The nuclear lamina is a meshwork of intermediate-type filaments. Nature 1986, 323, 560-564, doi:10.1038/323560a0.

3. Martins, F.; Sousa, J.; Pereira, C. D.; da Cruz E Silva, O. A. B.; Rebelo, S. Nuclear envelope dysfunction and its contribution to the aging process. Aging Cell 2020, e13143, doi:10.1111/acel.13143.

4. Robijns, J.; Houthaeve, G.; Braeckmans, K.; De Vos, W. H. Loss of nuclear envelope integrity in aging and disease. Int. Rev. Cell Mol. Biol. 2018, 336, 205-222, doi:10.1016/bs.ircmb.2017.07.013.

5. Hozák, P.; Sasseville, A. M.; Raymond, Y.; Cook, P. R. Lamin proteins form an internal nucleoskeleton as well as a peripheral lamina in human cells. J. Cell Sci. 1995, 108 (Pt 2), 635-644.

6. Gruenbaum, Y.; Foisner, R. Lamins: nuclear intermediate filament proteins with fundamental functions in nuclear mechanics and genome regulation. Annu. Rev. Biochem. 2015, 84, 131-164, doi:10.1146/annurevbiochem-060614-034115.

7. Crisp, M.; Burke, B. The nuclear envelope as an integrator of nuclear and cytoplasmic architecture. FEBS Lett. 2008, 582, 2023-2032, doi:10.1016/j.febslet.2008.05.001.

8. Markiewicz, E.; Dechat, T.; Foisner, R.; Quinlan, R. A.; Hutchison, C. J. Lamin A/C binding protein LAP2alpha is required for nuclear anchorage of retinoblastoma protein. Mol. Biol. Cell 2002, 13, 4401-4413, doi:10.1091/mbc.E02-07-0450.

9. Dorner, D.; Gotzmann, J.; Foisner, R. Nucleoplasmic lamins and their interaction partners, LAP2 $\alpha$, Rb, and $\mathrm{BAF}$, in transcriptional regulation. The FEBS Journal 2007.

10. Lund, E.; Collas, P. Nuclear lamins: making contacts with promoters. Nucleus 2013, 4, 424-430, doi:10.4161/nucl.26865.

11. Zheng, X.; Hu, J.; Yue, S.; Kristiani, L.; Kim, M.; Sauria, M.; Taylor, J.; Kim, Y.; Zheng, Y. Lamins Organize the Global Three-Dimensional Genome from the Nuclear Periphery. Mol. Cell 2018, 71, 802-815.e7, doi:10.1016/j.molcel.2018.05.017. 
12. Kristiani, L.; Kim, M.; Kim, Y. Role of the Nuclear Lamina in Age-Associated Nuclear Reorganization and Inflammation. Cells 2020, 9, doi:10.3390/cells9030718.

13. Ivorra, C.; Kubicek, M.; González, J. M.; Sanz-González, S. M.; Alvarez-Barrientos, A.; O’Connor, J.-E.; Burke, B.; Andrés, V. A mechanism of AP-1 suppression through interaction of c-Fos with lamin A/C. Genes Dev. 2006, 20, 307-320, doi:10.1101/gad.349506.

14. Crisp, M.; Liu, Q.; Roux, K.; Rattner, J. B.; Shanahan, C.; Burke, B.; Stahl, P. D.; Hodzic, D. Coupling of the nucleus and cytoplasm: role of the LINC complex. J. Cell Biol. 2006, 172, 41-53, doi:10.1083/jcb.200509124.

15. Lee, J. S. H.; Hale, C. M.; Panorchan, P.; Khatau, S. B.; George, J. P.; Tseng, Y.; Stewart, C. L.; Hodzic, D.; Wirtz, D. Nuclear lamin A/C deficiency induces defects in cell mechanics, polarization, and migration. Biophys. J. 2007, 93, 2542-2552, doi:10.1529/biophysj.106.102426.

16. Wong, X.; Stewart, C. L. The Laminopathies and the Insights They Provide into the Structural and Functional Organization of the Nucleus. Annu. Rev. Genomics Hum. Genet. 2020, doi:10.1146/annurevgenom-121219-083616.

17. Goldman, A. E.; Maul, G.; Steinert, P. M.; Yang, H. Y.; Goldman, R. D. Keratin-like proteins that coisolate with intermediate filaments of BHK-21 cells are nuclear lamins. Proc Natl Acad Sci USA 1986, 83, 38393843, doi:10.1073/pnas.83.11.3839.

18. Fisher, D. Z.; Chaudhary, N.; Blobel, G. cDNA sequencing of nuclear lamins A and C reveals primary and secondary structural homology to intermediate filament proteins. Proc Natl Acad Sci USA 1986, 83, 64506454, doi:10.1073/pnas.83.17.6450.

19. Dhe-Paganon, S.; Werner, E. D.; Chi, Y.-I.; Shoelson, S. E. Structure of the globular tail of nuclear lamin. J. Biol. Chem. 2002, 277, 17381-17384, doi:10.1074/jbc.C200038200.

20. Young, S. G.; Fong, L. G.; Michaelis, S. Prelamin A, Zmpste24, misshapen cell nuclei, and progeria--new evidence suggesting that protein farnesylation could be important for disease pathogenesis. J. Lipid Res. 2005, 46, 2531-2558, doi:10.1194/jlr.R500011-JLR200.

21. Rusiñol, A. E.; Sinensky, M. S. Farnesylated lamins, progeroid syndromes and farnesyl transferase inhibitors. J. Cell Sci. 2006, 119, 3265-3272, doi:10.1242/jcs.03156.

22. Furukawa, K.; Inagaki, H.; Hotta, Y. Identification and cloning of an mRNA coding for a germ cell-specific A-type lamin in mice. Exp. Cell Res. 1994, 212, 426-430, doi:10.1006/excr.1994.1164.

23. Furukawa, K.; Hotta, Y. cDNA cloning of a germ cell specific lamin B3 from mouse spermatocytes and analysis of its function by ectopic expression in somatic cells. EMBO J. 1993, 12, 97-106, doi:10.1002/j.14602075.1993.tb05635.x.

24. Stuurman, N.; Heins, S.; Aebi, U. Nuclear lamins: their structure, assembly, and interactions. J. Struct. Biol. 1998, 122, 42-66, doi:10.1006/jsbi.1998.3987.

25. Bridger, J. M.; Kill, I. R.; O'Farrell, M.; Hutchison, C. J. Internal lamin structures within G1 nuclei of human dermal fibroblasts. J. Cell Sci. 1993, 104 (Pt 2), 297-306.

26. Holaska, J. M.; Wilson, K. L.; Mansharamani, M. The nuclear envelope, lamins and nuclear assembly. Curr. Opin. Cell Biol. 2002, 14, 357-364, doi:10.1016/S0955-0674(02)00329-0.

27. Turgay, Y.; Eibauer, M.; Goldman, A. E.; Shimi, T.; Khayat, M.; Ben-Harush, K.; Dubrovsky-Gaupp, A.; Sapra, K. T.; Goldman, R. D.; Medalia, O. The molecular architecture of lamins in somatic cells. Nature 2017, 543, 261-264, doi:10.1038/nature21382.

28. Shimi, T.; Kittisopikul, M.; Tran, J.; Goldman, A. E.; Adam, S. A.; Zheng, Y.; Jaqaman, K.; Goldman, R. D. Structural organization of nuclear lamins A, C, B1, and B2 revealed by superresolution microscopy. Mol. Biol. Cell 2015, 26, 4075-4086, doi:10.1091/mbc.E15-07-0461.

29. Schermelleh, L.; Carlton, P. M.; Haase, S.; Shao, L.; Winoto, L.; Kner, P.; Burke, B.; Cardoso, M. C.; Agard, D. A.; Gustafsson, M. G. L.; Leonhardt, H.; Sedat, J. W. Subdiffraction multicolor imaging of the nuclear periphery with 3D structured illumination microscopy. Science 2008, 320, 1332-1336, doi:10.1126/science.1156947.

30. Nmezi, B.; Xu, J.; Fu, R.; Armiger, T. J.; Rodriguez-Bey, G.; Powell, J. S.; Ma, H.; Sullivan, M.; Tu, Y.; Chen, N. Y.; Young, S. G.; Stolz, D. B.; Dahl, K. N.; Liu, Y.; Padiath, Q. S. Concentric organization of A- and B-type lamins predicts their distinct roles in the spatial organization and stability of the nuclear lamina. Proc Natl Acad Sci USA 2019, 116, 4307-4315, doi:10.1073/pnas.1810070116.

31. Dechat, T.; Gesson, K.; Foisner, R. Lamina-independent lamins in the nuclear interior serve important functions. Cold Spring Harb. Symp. Quant. Biol. 2010, 75, 533-543, doi:10.1101/sqb.2010.75.018.

32. Uchino, R.; Sugiyama, S.; Katagiri, M.; Chuman, Y.; Furukawa, K. Non-farnesylated B-type lamin can tether chromatin inside the nucleus and its chromatin interaction requires the Ig-fold region. Chromosoma 2017, 126, 125-144, doi:10.1007/s00412-016-0581-x. 
33. Takeshi, S.; Pack, C.-G.; Goldman, R. D. Analyses of the dynamic properties of nuclear lamins by fluorescence recovery after photobleaching (FRAP) and fluorescence correlation spectroscopy (FCS). Methods Mol. Biol. 2016, 1411, 99-111, doi:10.1007/978-1-4939-3530-7_5.

34. Shimi, T.; Pfleghaar, K.; Kojima, S.; Pack, C.-G.; Solovei, I.; Goldman, A. E.; Adam, S. A.; Shumaker, D. K.; Kinjo, M.; Cremer, T.; Goldman, R. D. The A- and B-type nuclear lamin networks: microdomains involved in chromatin organization and transcription. Genes Dev. 2008, 22, 3409-3421, doi:10.1101/gad.1735208.

35. Swift, J.; Ivanovska, I. L.; Buxboim, A.; Harada, T.; Dingal, P. C. D. P.; Pinter, J.; Pajerowski, J. D.; Spinler, K. R.; Shin, J.-W.; Tewari, M.; Rehfeldt, F.; Speicher, D. W.; Discher, D. E. Nuclear lamin-A scales with tissue stiffness and enhances matrix-directed differentiation. Science 2013, 341, 1240104, doi:10.1126/science.1240104.

36. Buxboim, A.; Irianto, J.; Swift, J.; Athirasala, A.; Shin, J.-W.; Rehfeldt, F.; Discher, D. E. Coordinated increase of nuclear tension and lamin-A with matrix stiffness outcompetes lamin-B receptor that favors soft tissue phenotypes. Mol. Biol. Cell 2017, 28, 3333-3348, doi:10.1091/mbc.E17-06-0393.

37. Dechat, T.; Gajewski, A.; Korbei, B.; Gerlich, D.; Daigle, N.; Haraguchi, T.; Furukawa, K.; Ellenberg, J.; Foisner, R. LAP2alpha and BAF transiently localize to telomeres and specific regions on chromatin during nuclear assembly. J. Cell Sci. 2004, 117, 6117-6128, doi:10.1242/jcs.01529.

38. Brachner, A.; Foisner, R. Lamina-associated polypeptide (LAP) $2 \alpha$ and other LEM proteins in cancer biology. Adv. Exp. Med. Biol. 2014, 773, 143-163, doi:10.1007/978-1-4899-8032-8_7.

39. Furukawa, K.; Sugiyama, S.; Osouda, S.; Goto, H.; Inagaki, M.; Horigome, T.; Omata, S.; McConnell, M.; Fisher, P. A.; Nishida, Y. Barrier-to-autointegration factor plays crucial roles in cell cycle progression and nuclear organization in Drosophila. J. Cell Sci. 2003, 116, 3811-3823, doi:10.1242/jcs.00682.

40. Skoko, D.; Li, M.; Huang, Y.; Mizuuchi, M.; Cai, M.; Bradley, C. M.; Pease, P. J.; Xiao, B.; Marko, J. F.; Craigie, R.; Mizuuchi, K. Barrier-to-autointegration factor (BAF) condenses DNA by looping. Proc Natl Acad Sci USA 2009, 106, 16610-16615, doi:10.1073/pnas.0909077106.

41. Somech, R.; Shaklai, S.; Geller, O.; Amariglio, N.; Simon, A. J.; Rechavi, G.; Gal-Yam, E. N. The nuclearenvelope protein and transcriptional repressor LAP2beta interacts with HDAC3 at the nuclear periphery, and induces histone H4 deacetylation. J. Cell Sci. 2005, 118, 4017-4025, doi:10.1242/jcs.02521.

42. Barton, L. J.; Soshnev, A. A.; Geyer, P. K. Networking in the nucleus: a spotlight on LEM-domain proteins. Curr. Opin. Cell Biol. 2015, 34, 1-8, doi:10.1016/j.ceb.2015.03.005.

43. Giannios, I.; Chatzantonaki, E.; Georgatos, S. Dynamics and Structure-Function Relationships of the Lamin B Receptor (LBR). PLoS ONE 2017, 12, e0169626, doi:10.1371/journal.pone.0169626.

44. Ye, Q.; Worman, H. J. Primary structure analysis and lamin B and DNA binding of human LBR, an integral protein of the nuclear envelope inner membrane. J. Biol. Chem. 1994, 269, 11306-11311.

45. Hirano, Y.; Hizume, K.; Kimura, H.; Takeyasu, K.; Haraguchi, T.; Hiraoka, Y. Lamin B receptor recognizes specific modifications of histone H4 in heterochromatin formation. J. Biol. Chem. 2012, 287, 42654-42663, doi:10.1074/jbc.M112.397950.

46. Solovei, I.; Wang, A. S.; Thanisch, K.; Schmidt, C. S.; Krebs, S.; Zwerger, M.; Cohen, T. V.; Devys, D.; Foisner, R.; Peichl, L.; Herrmann, H.; Blum, H.; Engelkamp, D.; Stewart, C. L.; Leonhardt, H.; Joffe, B. LBR and lamin $\mathrm{A} / \mathrm{C}$ sequentially tether peripheral heterochromatin and inversely regulate differentiation. Cell 2013, 152, 584-598, doi:10.1016/j.cell.2013.01.009.

47. Worman, H. J.; Schirmer, E. C. Nuclear membrane diversity: underlying tissue-specific pathologies in disease? Curr. Opin. Cell Biol. 2015, 34, 101-112, doi:10.1016/j.ceb.2015.06.003.

48. Korfali, N.; Wilkie, G. S.; Swanson, S. K.; Srsen, V.; de Las Heras, J.; Batrakou, D. G.; Malik, P.; Zuleger, N.; Kerr, A. R. W.; Florens, L.; Schirmer, E. C. The nuclear envelope proteome differs notably between tissues. Nucleus 2012, 3, 552-564, doi:10.4161/nucl.22257.

49. Kim, D. I.; Birendra, K. C.; Roux, K. J. Making the LINC: SUN and KASH protein interactions. Biol. Chem. 2015, 396, 295-310, doi:10.1515/hsz-2014-0267.

50. Uzer, G.; Rubin, C. T.; Rubin, J. Cell mechanosensitivity is enabled by the LINC nuclear complex. Curr. Mol. Biol. Rep. 2016, 2, 36-47, doi:10.1007/s40610-016-0032-8.

51. Chang, W.; Antoku, S.; Östlund, C.; Worman, H. J.; Gundersen, G. G. Linker of nucleoskeleton and cytoskeleton (LINC) complex-mediated actin-dependent nuclear positioning orients centrosomes in migrating myoblasts. Nucleus 2015, 6, 77-88, doi:10.1080/19491034.2015.1004947.

52. Burke, B. LINC complexes as regulators of meiosis. Curr. Opin. Cell Biol. 2018, 52, 22-29, doi:10.1016/j.ceb.2018.01.005.

53. Guo, Y.; Zheng, Y. Lamins position the nuclear pores and centrosomes by modulating dynein. Mol. Biol. Cell 2015, 26, 3379-3389, doi:10.1091/mbc.E15-07-0482. 
54. Xie, W.; Chojnowski, A.; Boudier, T.; Lim, J. S. Y.; Ahmed, S.; Ser, Z.; Stewart, C.; Burke, B. A-type Lamins Form Distinct Filamentous Networks with Differential Nuclear Pore Complex Associations. Curr. Biol. 2016, 26, 2651-2658, doi:10.1016/j.cub.2016.07.049.

55. Kind, J.; van Steensel, B. Genome-nuclear lamina interactions and gene regulation. Curr. Opin. Cell Biol. 2010, 22, 320-325, doi:10.1016/j.ceb.2010.04.002.

56. Kubben, N.; Voncken, J. W.; Misteli, T. Mapping of protein- and chromatin-interactions at the nuclear lamina. Nucleus 2010, 1, 460-471, doi:10.4161/nucl.1.6.13513.

57. Zwerger, M.; Medalia, O. From lamins to lamina: a structural perspective. Histochem. Cell Biol. 2013, 140, 3-12, doi:10.1007/s00418-013-1104-y.

58. Graham, D. M.; Burridge, K. Mechanotransduction and nuclear function. Curr. Opin. Cell Biol. 2016, 40, 98-105, doi:10.1016/j.ceb.2016.03.006.

59. Chu, F.-Y.; Haley, S. C.; Zidovska, A. On the origin of shape fluctuations of the cell nucleus. Proc Natl Acad Sci USA 2017, 114, 10338-10343, doi:10.1073/pnas.1702226114.

60. Lenz-Böhme, B.; Wismar, J.; Fuchs, S.; Reifegerste, R.; Buchner, E.; Betz, H.; Schmitt, B. Insertional mutation of the Drosophila nuclear lamin Dm0 gene results in defective nuclear envelopes, clustering of nuclear pore complexes, and accumulation of annulate lamellae. J. Cell Biol. 1997, 137, 1001-1016, doi:10.1083/jcb.137.5.1001.

61. Liu, J.; Ben-Shahar, T. R.; Riemer, D.; Treinin, M.; Spann, P.; Weber, K.; Fire, A.; Gruenbaum, Y. Essential Roles forCaenorhabditis elegans Lamin Gene in Nuclear Organization, Cell Cycle Progression, and Spatial Organization of Nuclear Pore Complexes. Mol. Biol. Cell 2000, 11, 3937-3947, doi:10.1091/mbc.11.11.3937.

62. Sullivan, T.; Escalante-Alcalde, D.; Bhatt, H.; Anver, M.; Bhat, N.; Nagashima, K.; Stewart, C. L.; Burke, B. Loss of A-type lamin expression compromises nuclear envelope integrity leading to muscular dystrophy. J. Cell Biol. 1999, 147, 913-920, doi:10.1083/jcb.147.5.913.

63. van Engelen, B. G. M.; Muchir, A.; Hutchison, C. J.; van der Kooi, A. J.; Bonne, G.; Lammens, M. The lethal phenotype of a homozygous nonsense mutation in the lamin A/C gene. Neurology 2005, 64, 374-376, doi:10.1212/01.WNL.0000149763.15180.00.

64. De Vos, W. H.; Houben, F.; Kamps, M.; Malhas, A.; Verheyen, F.; Cox, J.; Manders, E. M. M.; Verstraeten, V. L. R. M.; van Steensel, M. A. M.; Marcelis, C. L. M.; van den Wijngaard, A.; Vaux, D. J.; Ramaekers, F. C. S.; Broers, J. L. V. Repetitive disruptions of the nuclear envelope invoke temporary loss of cellular compartmentalization in laminopathies. Hum. Mol. Genet. 2011, 20, 4175-4186, doi:10.1093/hmg/ddr344.

65. Stephens, A. D.; Liu, P. Z.; Kandula, V.; Chen, H.; Almassalha, L. M.; Herman, C.; Backman, V.; O’Halloran, T.; Adam, S. A.; Goldman, R. D.; Banigan, E. J.; Marko, J. F. Physicochemical mechanotransduction alters nuclear shape and mechanics via heterochromatin formation. Mol. Biol. Cell 2019, 30, 2320-2330, doi:10.1091/mbc.E19-05-0286.

66. Ferrera, D.; Canale, C.; Marotta, R.; Mazzaro, N.; Gritti, M.; Mazzanti, M.; Capellari, S.; Cortelli, P.; Gasparini, L. Lamin B1 overexpression increases nuclear rigidity in autosomal dominant leukodystrophy fibroblasts. FASEB J. 2014, 28, 3906-3918, doi:10.1096/fj.13-247635.

67. Wintner, O.; Hirsch-Attas, N.; Schlossberg, M.; Brofman, F.; Friedman, R.; Kupervaser, M.; Kitsberg, D.; Buxboim, A. A unified linear viscoelastic model of the cell nucleus defines the mechanical contributions of lamins and chromatin. Adv Sci (Weinh) 2020, 7, 1901222, doi:10.1002/advs.201901222.

68. Stephens, A. D.; Banigan, E. J.; Adam, S. A.; Goldman, R. D.; Marko, J. F. Chromatin and lamin A determine two different mechanical response regimes of the cell nucleus. Mol. Biol. Cell 2017, 28, 1984-1996, doi:10.1091/mbc.E16-09-0653.

69. Goldberg, M. W.; Huttenlauch, I.; Hutchison, C. J.; Stick, R. Filaments made from A- and B-type lamins differ in structure and organization. J. Cell Sci. 2008, 121, 215-225, doi:10.1242/jcs.022020.

70. Lammerding, J.; Lee, R. T. The nuclear membrane and mechanotransduction: impaired nuclear mechanics and mechanotransduction in lamin A/C deficient cells. Novartis Found. Symp. 2005, 264, 264-73; discussion 273.

71. Liu, L.; Luo, Q.; Sun, J.; Song, G. Nucleus and nucleus-cytoskeleton connections in 3D cell migration. Exp. Cell Res. 2016, 348, 56-65, doi:10.1016/j.yexcr.2016.09.001.

72. Jung, H.-J.; Nobumori, C.; Goulbourne, C. N.; Tu, Y.; Lee, J. M.; Tatar, A.; Wu, D.; Yoshinaga, Y.; de Jong, P. J.; Coffinier, C.; Fong, L. G.; Young, S. G. Farnesylation of lamin B1 is important for retention of nuclear chromatin during neuronal migration. Proc Natl Acad Sci USA 2013, 110, E1923-32, doi:10.1073/pnas.1303916110.

73. Chen, N. Y.; Yang, Y.; Weston, T. A.; Belling, J. N.; Heizer, P.; Tu, Y.; Kim, P.; Edillo, L.; Jonas, S. J.; Weiss, P. S.; Fong, L. G.; Young, S. G. An absence of lamin B1 in migrating neurons causes nuclear membrane ruptures and cell death. Proc Natl Acad Sci USA 2019, 116, 25870-25879, doi:10.1073/pnas.1917225116. 
74. Naetar, N.; Ferraioli, S.; Foisner, R. Lamins in the nuclear interior - life outside the lamina. J. Cell Sci. 2017, 130, 2087-2096, doi:10.1242/jcs.203430.

75. Legartová, S.; Stixová, L.; Laur, O.; Kozubek, S.; Sehnalová, P.; Bártová, E. Nuclear structures surrounding internal lamin invaginations. J. Cell. Biochem. 2014, 115, 476-487, doi:10.1002/jcb.24681.

76. Rout, M. P.; Field, M. C. Isolation and characterization of subnuclear compartments from Trypanosoma brucei. Identification of a major repetitive nuclear lamina component. J. Biol. Chem. 2001, 276, 38261-38271, doi:10.1074/jbc.M104024200.

77. Stixová, L.; Matula, P.; Kozubek, S.; Gombitová, A.; Cmarko, D.; Raška, I.; Bártová, E. Trajectories and nuclear arrangement of PML bodies are influenced by A-type lamin deficiency. Biol. Cell 2012, 104, 418432, doi:10.1111/boc.201100053.

78. Sen Gupta, A.; Sengupta, K. Lamin B2 modulates nucleolar morphology, dynamics, and function. Mol. Cell. Biol. 2017, 37, doi:10.1128/MCB.00274-17.

79. Hetzer, M. W.; Wente, S. R. Border control at the nucleus: biogenesis and organization of the nuclear membrane and pore complexes. Dev. Cell 2009, 17, 606-616, doi:10.1016/j.devcel.2009.10.007.

80. Cremer, T.; Cremer, C.; Baumann, H.; Luedtke, E. K.; Sperling, K.; Teuber, V.; Zorn, C. Rabl's model of the interphase chromosome arrangement tested in Chinese hamster cells by premature chromosome condensation and laser-UV-microbeam experiments. Hum. Genet. 1982, 60, 46-56, doi:10.1007/bf00281263.

81. Cremer, T.; Cremer, C. Chromosome territories, nuclear architecture and gene regulation in mammalian cells. Nat. Rev. Genet. 2001, 2, 292-301, doi:10.1038/35066075.

82. Guelen, L.; Pagie, L.; Brasset, E.; Meuleman, W.; Faza, M. B.; Talhout, W.; Eussen, B. H.; de Klein, A.; Wessels, L.; de Laat, W.; van Steensel, B. Domain organization of human chromosomes revealed by mapping of nuclear lamina interactions. Nature 2008, 453, 948-951, doi:10.1038/nature06947.

83. Zullo, J. M.; Demarco, I. A.; Piqué-Regi, R.; Gaffney, D. J.; Epstein, C. B.; Spooner, C. J.; Luperchio, T. R.; Bernstein, B. E.; Pritchard, J. K.; Reddy, K. L.; Singh, H. DNA sequence-dependent compartmentalization and silencing of chromatin at the nuclear lamina. Cell 2012, 149, 1474-1487, doi:10.1016/j.cell.2012.04.035.

84. Kind, J.; Pagie, L.; de Vries, S. S.; Nahidiazar, L.; Dey, S. S.; Bienko, M.; Zhan, Y.; Lajoie, B.; de Graaf, C. A.; Amendola, M.; Fudenberg, G.; Imakaev, M.; Mirny, L. A.; Jalink, K.; Dekker, J.; van Oudenaarden, A.; van Steensel, B. Genome-wide maps of nuclear lamina interactions in single human cells. Cell 2015, 163, 134147, doi:10.1016/j.cell.2015.08.040.

85. Lochs, S. J. A.; Kefalopoulou, S.; Kind, J. Lamina associated domains and gene regulation in development and cancer. Cells 2019, 8, doi:10.3390/cells8030271.

86. Borsos, M.; Perricone, S. M.; Schauer, T.; Pontabry, J.; de Luca, K. L.; de Vries, S. S.; Ruiz-Morales, E. R.; Torres-Padilla, M.-E.; Kind, J. Genome-lamina interactions are established de novo in the early mouse embryo. Nature 2019, 569, 729-733, doi:10.1038/s41586-019-1233-0.

87. Siersbæk, R.; Madsen, J. G. S.; Javierre, B. M.; Nielsen, R.; Bagge, E. K.; Cairns, J.; Wingett, S. W.; Traynor, S.; Spivakov, M.; Fraser, P.; Mandrup, S. Dynamic Rewiring of Promoter-Anchored Chromatin Loops during Adipocyte Differentiation. Mol. Cell 2017, 66, 420-435.e5, doi:10.1016/j.molcel.2017.04.010.

88. Baricheva, E. A.; Berrios, M.; Bogachev, S. S.; Borisevich, I. V.; Lapik, E. R.; Sharakhov, I. V.; Stuurman, N.; Fisher, P. A. DNA from Drosophila melanogaster $\beta$-heterochromatin binds specifically to nuclear lamins in vitro and the nuclear envelope in situ. Gene 1996, 171, 171-176, doi:10.1016/0378-1119(96)00002-9.

89. Duband-Goulet, I. Lamin ChIP from Chromatin Prepared by Micrococcal Nuclease Digestion. Methods Mol. Biol. 2016, 1411, 325-339, doi:10.1007/978-1-4939-3530-7_21.

90. Bronshtein, I.; Kepten, E.; Kanter, I.; Berezin, S.; Lindner, M.; Redwood, A. B.; Mai, S.; Gonzalo, S.; Foisner, R.; Shav-Tal, Y.; Garini, Y. Loss of lamin A function increases chromatin dynamics in the nuclear interior. Nat. Commun. 2015, 6, 8044, doi:10.1038/ncomms9044.

91. Yáñez-Cuna, J. O.; van Steensel, B. Genome-nuclear lamina interactions: from cell populations to single cells. Curr. Opin. Genet. Dev. 2017, 43, 67-72, doi:10.1016/j.gde.2016.12.005.

92. Kind, J.; Pagie, L.; Ortabozkoyun, H.; Boyle, S.; de Vries, S. S.; Janssen, H.; Amendola, M.; Nolen, L. D.; Bickmore, W. A.; van Steensel, B. Single-cell dynamics of genome-nuclear lamina interactions. Cell 2013, 153, 178-192, doi:10.1016/j.cell.2013.02.028.

93. Taniura, H.; Glass, C.; Gerace, L. A chromatin binding site in the tail domain of nuclear lamins that interacts with core histones. J. Cell Biol. 1995, 131, 33-44, doi:10.1083/jcb.131.1.33.

94. Meuleman, W.; Peric-Hupkes, D.; Kind, J.; Beaudry, J.-B.; Pagie, L.; Kellis, M.; Reinders, M.; Wessels, L.; van Steensel, B. Constitutive nuclear lamina-genome interactions are highly conserved and associated with A/T-rich sequence. Genome Res. 2013, 23, 270-280, doi:10.1101/gr.141028.112.

95. Kind, J.; van Steensel, B. Stochastic genome-nuclear lamina interactions: modulating roles of Lamin A and BAF. Nucleus 2014, 5, 124-130, doi:10.4161/nucl.28825. 
96. Mislow, J. M. .; Holaska, J. M.; Kim, M. S.; Lee, K. K.; Segura-Totten, M.; Wilson, K. L.; McNally, E. M. Nesprin-1 $\alpha$ self-associates and binds directly to emerin and lamin A in vitro. FEBS Lett. 2002, 525, 135-140, doi:10.1016/S0014-5793(02)03105-8.

97. Ranade, D.; Koul, S.; Thompson, J.; Prasad, K. B.; Sengupta, K. Chromosomal aneuploidies induced upon Lamin B2 depletion are mislocalized in the interphase nucleus. Chromosoma 2017, 126, 223-244, doi:10.1007/s00412-016-0580-y.

98. Forsberg, F.; Brunet, A.; Ali, T. M. L.; Collas, P. Interplay of lamin A and lamin B LADs on the radial positioning of chromatin. Nucleus 2019, 10, 7-20, doi:10.1080/19491034.2019.1570810.

99. Robson, M. I.; de Las Heras, J. I.; Czapiewski, R.; Sivakumar, A.; Kerr, A. R. W.; Schirmer, E. C. Constrained release of lamina-associated enhancers and genes from the nuclear envelope during T-cell activation facilitates their association in chromosome compartments. Genome Res. 2017, 27, 1126-1138, doi:10.1101/gr.212308.116.

100. Chang, L.; Li, M.; Shao, S.; Xue, B.; Hou, Y.; Zhang, Y.; Li, R.; Li, C.; Sun, Y. Chromatin-lamin B1 interaction promotes genomic compartmentalization and constrains chromatin dynamics. BioRxiv 2019, doi:10.1101/601849.

101. van Steensel, B.; Delrow, J.; Henikoff, S. Chromatin profiling using targeted DNA adenine methyltransferase. Nat. Genet. 2001, 27, 304-308, doi:10.1038/85871.

102. Talamas, J. A.; Capelson, M. Nuclear envelope and genome interactions in cell fate. Front. Genet. 2015, 6, 95, doi:10.3389/fgene.2015.00095.

103. Becker, J. S.; Nicetto, D.; Zaret, K. S. H3K9me3-Dependent Heterochromatin: Barrier to Cell Fate Changes. Trends Genet. 2016, 32, 29-41, doi:10.1016/j.tig.2015.11.001.

104. Gonzalez-Sandoval, A.; Towbin, B. D.; Kalck, V.; Cabianca, D. S.; Gaidatzis, D.; Hauer, M. H.; Geng, L.; Wang, L.; Yang, T.; Wang, X.; Zhao, K.; Gasser, S. M. Perinuclear Anchoring of H3K9-Methylated Chromatin Stabilizes Induced Cell Fate in C. elegans Embryos. Cell 2015, 163, 1333-1347, doi:10.1016/j.cell.2015.10.066.

105. Rønningen, T.; Shah, A.; Oldenburg, A. R.; Vekterud, K.; Delbarre, E.; Moskaug, J. Ø.; Collas, P. Prepatterning of differentiation-driven nuclear lamin A/C-associated chromatin domains by GlcNAcylated histone H2B. Genome Res. 2015, 25, 1825-1835, doi:10.1101/gr.193748.115.

106. Dahl, K. N.; Scaffidi, P.; Islam, M. F.; Yodh, A. G.; Wilson, K. L.; Misteli, T. Distinct structural and mechanical properties of the nuclear lamina in Hutchinson-Gilford progeria syndrome. Proc Natl Acad Sci USA 2006, 103, 10271-10276, doi:10.1073/pnas.0601058103.

107. Taimen, P.; Pfleghaar, K.; Shimi, T.; Möller, D.; Ben-Harush, K.; Erdos, M. R.; Adam, S. A.; Herrmann, H.; Medalia, O.; Collins, F. S.; Goldman, A. E.; Goldman, R. D. A progeria mutation reveals functions for lamin A in nuclear assembly, architecture, and chromosome organization. Proc Natl Acad Sci USA 2009, 106, 20788-20793, doi:10.1073/pnas.0911895106.

108. Shevelyov, Y. Y.; Lavrov, S. A.; Mikhaylova, L. M.; Nurminsky, I. D.; Kulathinal, R. J.; Egorova, K. S.; Rozovsky, Y. M.; Nurminsky, D. I. The B-type lamin is required for somatic repression of testis-specific gene clusters. Proc Natl Acad Sci USA 2009, 106, 3282-3287, doi:10.1073/pnas.0811933106.

109. Ulianov, S. V.; Doronin, S. A.; Khrameeva, E. E.; Kos, P. I.; Luzhin, A. V.; Starikov, S. S.; Galitsyna, A. A.; Nenasheva, V. V.; Ilyin, A. A.; Flyamer, I. M.; Mikhaleva, E. A.; Logacheva, M. D.; Gelfand, M. S.; Chertovich, A. V.; Gavrilov, A. A.; Razin, S. V.; Shevelyov, Y. Y. Nuclear lamina integrity is required for proper spatial organization of chromatin in Drosophila. Nat. Commun. 2019, 10, 1176, doi:10.1038/s41467019-09185-y.

110. Malhas, A.; Lee, C. F.; Sanders, R.; Saunders, N. J.; Vaux, D. J. Defects in lamin B1 expression or processing affect interphase chromosome position and gene expression. J. Cell Biol. 2007, 176, 593-603, doi:10.1083/jcb.200607054.

111. Camps, J.; Wangsa, D.; Falke, M.; Brown, M.; Case, C. M.; Erdos, M. R.; Ried, T. Loss of lamin B1 results in prolongation of S phase and decondensation of chromosome territories. FASEB J. 2014, 28, 3423-3434, doi:10.1096/fj.14-250456.

112. Meaburn, K. J.; Cabuy, E.; Bonne, G.; Levy, N.; Morris, G. E.; Novelli, G.; Kill, I. R.; Bridger, J. M. Primary laminopathy fibroblasts display altered genome organization and apoptosis. Aging Cell 2007, 6, 139-153, doi:10.1111/j.1474-9726.2007.00270.x.

113. Dundr, M.; Ospina, J. K.; Sung, M.-H.; John, S.; Upender, M.; Ried, T.; Hager, G. L.; Matera, A. G. Actindependent intranuclear repositioning of an active gene locus in vivo. J. Cell Biol. 2007, 179, 1095-1103, doi:10.1083/jcb.200710058.

114. Mehta, I. S.; Elcock, L. S.; Amira, M.; Kill, I. R.; Bridger, J. M. Nuclear motors and nuclear structures containing A-type lamins and emerin: is there a functional link? Biochem. Soc. Trans. 2008, 36, 1384-1388, doi:10.1042/BST0361384. 
115. Ranade, D.; Pradhan, R.; Jayakrishnan, M.; Hegde, S.; Sengupta, K. Lamin A/C and Emerin depletion impacts chromatin organization and dynamics in the interphase nucleus. BMC Mol and Cell Biol 2019, 20, 11, doi:10.1186/s12860-019-0192-5.

116. Akhtar, A.; Gasser, S. M. The nuclear envelope and transcriptional control. Nat. Rev. Genet. 2007, 8, 507517, doi:10.1038/nrg2122.

117. Reddy, K. L.; Zullo, J. M.; Bertolino, E.; Singh, H. Transcriptional repression mediated by repositioning of genes to the nuclear lamina. Nature 2008, 452, 243-247, doi:10.1038/nature06727.

118. Poleshko, A.; Shah, P. P.; Gupta, M.; Babu, A.; Morley, M. P.; Manderfield, L. J.; Ifkovits, J. L.; Calderon, D.; Aghajanian, H.; Sierra-Pagán, J. E.; Sun, Z.; Wang, Q.; Li, L.; Dubois, N. C.; Morrisey, E. E.; Lazar, M. A.; Smith, C. L.; Epstein, J. A.; Jain, R. Genome-Nuclear Lamina Interactions Regulate Cardiac Stem Cell Lineage Restriction. Cell 2017, 171, 573-587.e14, doi:10.1016/j.cell.2017.09.018.

119. Kohwi, M.; Lupton, J. R.; Lai, S.-L.; Miller, M. R.; Doe, C. Q. Developmentally regulated subnuclear genome reorganization restricts neural progenitor competence in Drosophila. Cell 2013, 152, 97-108, doi:10.1016/j.cell.2012.11.049.

120. Peric-Hupkes, D.; Meuleman, W.; Pagie, L.; Bruggeman, S. W. M.; Solovei, I.; Brugman, W.; Gräf, S.; Flicek, P.; Kerkhoven, R. M.; van Lohuizen, M.; Reinders, M.; Wessels, L.; van Steensel, B. Molecular maps of the reorganization of genome-nuclear lamina interactions during differentiation. Mol. Cell 2010, 38, 603-613, doi:10.1016/j.molcel.2010.03.016.

121. Toh, K. C.; Ramdas, N. M.; Shivashankar, G. V. Actin cytoskeleton differentially alters the dynamics of lamin A, HP1 $\alpha$ and $\mathrm{H} 2 \mathrm{~B}$ core histone proteins to remodel chromatin condensation state in living cells. Integr Biol (Camb) 2015, 7, 1309-1317, doi:10.1039/c5ib00027k.

122. Kumaran, R. I.; Muralikrishna, B.; Parnaik, V. K. Lamin A/C speckles mediate spatial organization of splicing factor compartments and RNA polymerase II transcription. J. Cell Biol. 2002, 159, 783-793, doi:10.1083/jcb.200204149.

123. Kosak, S. T.; Skok, J. A.; Medina, K. L.; Riblet, R.; Le Beau, M. M.; Fisher, A. G.; Singh, H. Subnuclear compartmentalization of immunoglobulin loci during lymphocyte development. Science 2002, 296, 158 162, doi:10.1126/science.1068768.

124. McCord, R. P.; Balajee, A. 3D genome organization influences the chromosome translocation pattern. Adv. Exp. Med. Biol. 2018, 1044, 113-133, doi:10.1007/978-981-13-0593-1_8.

125. Dorner, D.; Gotzmann, J.; Foisner, R. Nucleoplasmic lamins and their interaction partners, LAP2alpha, Rb, and BAF, in transcriptional regulation. FEBS J. 2007, 274, 1362-1373, doi:10.1111/j.1742-4658.2007.05695.x.

126. Nili, E.; Cojocaru, G. S.; Kalma, Y.; Ginsberg, D.; Copeland, N. G.; Gilbert, D. J.; Jenkins, N. A.; Berger, R.; Shaklai, S.; Amariglio, N.; Brok-Simoni, F.; Simon, A. J.; Rechavi, G. Nuclear membrane protein LAP2beta mediates transcriptional repression alone and together with its binding partner GCL (germ-cell-less). J. Cell Sci. 2001, 114, 3297-3307.

127. Marullo, F.; Cesarini, E.; Antonelli, L.; Gregoretti, F.; Oliva, G.; Lanzuolo, C. Nucleoplasmic Lamin A/C and Polycomb group of proteins: An evolutionarily conserved interplay. Nucleus 2016, 7, 103-111, doi:10.1080/19491034.2016.1157675.

128. Mattout-Drubezki, A.; Gruenbaum, Y. Dynamic interactions of nuclear lamina proteins with chromatin and transcriptional machinery. Cell. Mol. Life Sci. 2003, 60, 2053-2063, doi:10.1007/s00018-003-3038-3.

129. González, J. M.; Navarro-Puche, A.; Casar, B.; Crespo, P.; Andrés, V. Fast regulation of AP-1 activity through interaction of lamin A/C, ERK1/2, and c-Fos at the nuclear envelope. J. Cell Biol. 2008, 183, 653666, doi:10.1083/jcb.200805049.

130. Lee, D. C.; Welton, K. L.; Smith, E. D.; Kennedy, B. K. A-type nuclear lamins act as transcriptional repressors when targeted to promoters. Exp. Cell Res. 2009, 315, 996-1007, doi:10.1016/j.yexcr.2009.01.003.

131. Lund, E.; Oldenburg, A. R.; Delbarre, E.; Freberg, C. T.; Duband-Goulet, I.; Eskeland, R.; Buendia, B.; Collas, P. Lamin A/C-promoter interactions specify chromatin state-dependent transcription outcomes. Genome Res. 2013, 23, 1580-1589, doi:10.1101/gr.159400.113.

132. Wu, F.; Yao, J. Identifying Novel Transcriptional and Epigenetic Features of Nuclear Lamina-associated Genes. Sci. Rep. 2017, 7, 100, doi:10.1038/s41598-017-00176-x.

133. Malhas, A. N.; Lee, C. F.; Vaux, D. J. Lamin B1 controls oxidative stress responses via Oct-1. J. Cell Biol. 2009, 184, 45-55, doi:10.1083/jcb.200804155.

134. Flint Brodsly, N.; Bitman-Lotan, E.; Boico, O.; Shafat, A.; Monastirioti, M.; Gessler, M.; Delidakis, C.; Rincon-Arano, H.; Orian, A. The transcription factor Hey and nuclear lamins specify and maintain cell identity. elife 2019, 8, doi:10.7554/eLife.44745.

135. Pascual-Reguant, L.; Blanco, E.; Galan, S.; Le Dily, F.; Cuartero, Y.; Serra-Bardenys, G.; Di Carlo, V.; Iturbide, A.; Cebrià-Costa, J. P.; Nonell, L.; de Herreros, A. G.; Di Croce, L.; Marti-Renom, M. A.; Peiró, S. 
Lamin B1 mapping reveals the existence of dynamic and functional euchromatin lamin B1 domains. Nat. Commun. 2018, 9, 3420, doi:10.1038/s41467-018-05912-z.

136. Comaills, V.; Kabeche, L.; Morris, R.; Buisson, R.; Yu, M.; Madden, M. W.; LiCausi, J. A.; Boukhali, M.; Tajima, K.; Pan, S.; Aceto, N.; Sil, S.; Zheng, Y.; Sundaresan, T.; Yae, T.; Jordan, N. V.; Miyamoto, D. T.; Ting, D. T.; Ramaswamy, S.; Haas, W.; Maheswaran, S. Genomic Instability Is Induced by Persistent Proliferation of Cells Undergoing Epithelial-to-Mesenchymal Transition. Cell Rep. 2016, 17, 2632-2647, doi:10.1016/j.celrep.2016.11.022.

137. Pradhan, R.; Nallappa, M. J.; Sengupta, K. Lamin A/C modulates spatial organization and function of the Hsp70 gene locus via nuclear myosin I. J. Cell Sci. 2020, 133, doi:10.1242/jcs.236265.

138. Buxboim, A.; Swift, J.; Irianto, J.; Spinler, K. R.; Dingal, P. C. D. P.; Athirasala, A.; Kao, Y.-R. C.; Cho, S.; Harada, T.; Shin, J.-W.; Discher, D. E. Matrix elasticity regulates lamin-A,C phosphorylation and turnover with feedback to actomyosin. Curr. Biol. 2014, 24, 1909-1917, doi:10.1016/j.cub.2014.07.001.

139. Dingal, P. C. D. P.; Discher, D. E. Systems mechanobiology: tension-inhibited protein turnover is sufficient to physically control gene circuits. Biophys. J. 2014, 107, 2734-2743, doi:10.1016/j.bpj.2014.10.042.

140. Osada, S.-I.; Ohmori, S.; Taira, M. XMAN1, an inner nuclear membrane protein, antagonizes BMP signaling by interacting with Smad1 in Xenopus embryos. Development 2003, 130, 1783-1794, doi:10.1242/dev.00401.

141. Lin, F.; Morrison, J. M.; Wu, W.; Worman, H. J. MAN1, an integral protein of the inner nuclear membrane, binds Smad2 and Smad3 and antagonizes transforming growth factor-beta signaling. Hum. Mol. Genet. 2005, 14, 437-445, doi:10.1093/hmg/ddi040.

142. Pan, D.; Estévez-Salmerón, L. D.; Stroschein, S. L.; Zhu, X.; He, J.; Zhou, S.; Luo, K. The integral inner nuclear membrane protein MAN1 physically interacts with the R-Smad proteins to repress signaling by the transforming growth factor-\{beta\} superfamily of cytokines. J. Biol. Chem. 2005, 280, 15992-16001, doi:10.1074/jbc.M411234200.

143. Pekovic, V.; Harborth, J.; Broers, J. L. V.; Ramaekers, F. C. S.; van Engelen, B.; Lammens, M.; von Zglinicki, T.; Foisner, R.; Hutchison, C.; Markiewicz, E. Nucleoplasmic LAP2alpha-lamin A complexes are required to maintain a proliferative state in human fibroblasts. J. Cell Biol. 2007, 176, 163-172, doi:10.1083/jcb.200606139.

144. Torvaldson, E.; Kochin, V.; Eriksson, J. E. Phosphorylation of lamins determine their structural properties and signaling functions. Nucleus 2015, 6, 166-171, doi:10.1080/19491034.2015.1017167.

145. Pradhan, R.; Ranade, D.; Sengupta, K. Emerin modulates spatial organization of chromosome territories in cells on softer matrices. Nucleic Acids Res. 2018, 46, 5561-5586, doi:10.1093/nar/gky288.

146. Muchir, A.; Pavlidis, P.; Decostre, V.; Herron, A. J.; Arimura, T.; Bonne, G.; Worman, H. J. Activation of MAPK pathways links LMNA mutations to cardiomyopathy in Emery-Dreifuss muscular dystrophy. J. Clin. Invest. 2007, 117, 1282-1293, doi:10.1172/JCI29042.

147. Van Berlo, J. H.; Voncken, J. W.; Kubben, N.; Broers, J. L. V.; Duisters, R.; van Leeuwen, R. E. W.; Crijns, H. J. G. M.; Ramaekers, F. C. S.; Hutchison, C. J.; Pinto, Y. M. A-type lamins are essential for TGF-beta1 induced PP2A to dephosphorylate transcription factors. Hum. Mol. Genet. 2005, 14, 2839-2849, doi:10.1093/hmg/ddi316.

148. Muchir, A.; Pavlidis, P.; Bonne, G.; Hayashi, Y. K.; Worman, H. J. Activation of MAPK in hearts of EMD null mice: similarities between mouse models of $\mathrm{X}$-linked and autosomal dominant Emery Dreifuss muscular dystrophy. Hum. Mol. Genet. 2007, 16, 1884-1895, doi:10.1093/hmg/ddm137.

149. Scaffidi, P.; Misteli, T. Lamin A-dependent misregulation of adult stem cells associated with accelerated ageing. Nat. Cell Biol. 2008, 10, 452-459, doi:10.1038/ncb1708.

150. Santaguida, S.; Richardson, A.; Iyer, D. R.; M’Saad, O.; Zasadil, L.; Knouse, K. A.; Wong, Y. L.; Rhind, N.; Desai, A.; Amon, A. Chromosome Mis-segregation Generates Cell-Cycle-Arrested Cells with Complex Karyotypes that Are Eliminated by the Immune System. Dev. Cell 2017, 41, 638-651.e5, doi:10.1016/j.devcel.2017.05.022.

151. Trautmann, K.; Terdiman, J. P.; French, A. J.; Roydasgupta, R.; Sein, N.; Kakar, S.; Fridlyand, J.; Snijders, A. M.; Albertson, D. G.; Thibodeau, S. N.; Waldman, F. M. Chromosomal instability in microsatellite-unstable and stable colon cancer. Clin. Cancer Res. 2006, 12, 6379-6385, doi:10.1158/1078-0432.CCR-06-1248.

152. Bell, E. S.; Lammerding, J. Causes and consequences of nuclear envelope alterations in tumour progression. Eur. J. Cell Biol. 2016, 95, 449-464, doi:10.1016/j.ejcb.2016.06.007.

153. Graziano, S.; Kreienkamp, R.; Coll-Bonfill, N.; Gonzalo, S. Causes and consequences of genomic instability in laminopathies: Replication stress and interferon response. Nucleus 2018, 9, 258-275, doi:10.1080/19491034.2018.1454168.

154. Martin, C.; Chen, S.; Jackson, D. A. Inheriting nuclear organization: can nuclear lamins impart spatial memory during post-mitotic nuclear assembly? Chromosome Res. 2010, 18, 525-541, doi:10.1007/s10577010-9137-8. 
155. Denais, C. M.; Gilbert, R. M.; Isermann, P.; McGregor, A. L.; te Lindert, M.; Weigelin, B.; Davidson, P. M.; Friedl, P.; Wolf, K.; Lammerding, J. Nuclear envelope rupture and repair during cancer cell migration. Science 2016, 352, 353-358, doi:10.1126/science.aad7297.

156. Tsai, M.-Y.; Wang, S.; Heidinger, J. M.; Shumaker, D. K.; Adam, S. A.; Goldman, R. D.; Zheng, Y. A mitotic lamin B matrix induced by RanGTP required for spindle assembly. Science 2006, 311, 1887-1893, doi:10.1126/science.1122771.

157. Kuga, T.; Nie, H.; Kazami, T.; Satoh, M.; Matsushita, K.; Nomura, F.; Maeshima, K.; Nakayama, Y.; Tomonaga, T. Lamin B2 prevents chromosome instability by ensuring proper mitotic chromosome segregation. Oncogenesis 2014, 3, e94, doi:10.1038/oncsis.2014.6.

158. Qi, R.; Xu, N.; Wang, G.; Ren, H.; Li, S.; Lei, J.; Lin, Q.; Wang, L.; Gu, X.; Zhang, H.; Jiang, Q.; Zhang, C. The lamin-A/C-LAP2 $\alpha$-BAF1 protein complex regulates mitotic spindle assembly and positioning. J. Cell Sci. 2015, 128, 2830-2841, doi:10.1242/jcs.164566.

159. Butin-Israeli, V.; Adam, S. A.; Jain, N.; Otte, G. L.; Neems, D.; Wiesmüller, L.; Berger, S. L.; Goldman, R. D. Role of lamin b1 in chromatin instability. Mol. Cell. Biol. 2015, 35, 884-898, doi:10.1128/MCB.01145-14.

160. Capo-Chichi, C. D.; Yeasky, T. M.; Smith, E. R.; Xu, X.-X. Nuclear envelope structural defect underlies the main cause of aneuploidy in ovarian carcinogenesis. BMC Cell Biol. 2016, 17, 37, doi:10.1186/s12860-0160114-8.

161. Dechat, T.; Shimi, T.; Adam, S. A.; Rusinol, A. E.; Andres, D. A.; Spielmann, H. P.; Sinensky, M. S.; Goldman, R. D. Alterations in mitosis and cell cycle progression caused by a mutant lamin A known to accelerate human aging. Proc Natl Acad Sci USA 2007, 104, 4955-4960, doi:10.1073/pnas.0700854104.

162. Gonzalez-Suarez, I.; Redwood, A. B.; Perkins, S. M.; Vermolen, B.; Lichtensztejin, D.; Grotsky, D. A.; Morgado-Palacin, L.; Gapud, E. J.; Sleckman, B. P.; Sullivan, T.; Sage, J.; Stewart, C. L.; Mai, S.; Gonzalo, S. Novel roles for A-type lamins in telomere biology and the DNA damage response pathway. EMBO J. 2009, 28, 2414-2427, doi:10.1038/emboj.2009.196.

163. Gibbs-Seymour, I.; Markiewicz, E.; Bekker-Jensen, S.; Mailand, N.; Hutchison, C. J. Lamin A/C-dependent interaction with 53BP1 promotes cellular responses to DNA damage. Aging Cell 2015, 14, 162-169, doi:10.1111/acel.12258.

164. Crabbe, L.; Cesare, A. J.; Kasuboski, J. M.; Fitzpatrick, J. A. J.; Karlseder, J. Human telomeres are tethered to the nuclear envelope during postmitotic nuclear assembly. Cell Rep. 2012, 2, 1521-1529, doi:10.1016/j.celrep.2012.11.019.

165. Redwood, A. B.; Perkins, S. M.; Vanderwaal, R. P.; Feng, Z.; Biehl, K. J.; Gonzalez-Suarez, I.; MorgadoPalacin, L.; Shi, W.; Sage, J.; Roti-Roti, J. L.; Stewart, C. L.; Zhang, J.; Gonzalo, S. A dual role for A-type lamins in DNA double-strand break repair. Cell Cycle 2011, 10, 2549-2560, doi:10.4161/cc.10.15.16531.

166. Vidak, S.; Georgiou, K.; Fichtinger, P.; Naetar, N.; Dechat, T.; Foisner, R. Nucleoplasmic lamins define growth-regulating functions of lamina-associated polypeptide $2 \alpha$ in progeria cells. J. Cell Sci. 2018, 131, doi:10.1242/jcs.208462.

167. Chen, H.; Zheng, X.; Zheng, Y. Age-associated loss of lamin-B leads to systemic inflammation and gut hyperplasia. Cell 2014, 159, 829-843, doi:10.1016/j.cell.2014.10.028.

168. Rao, L.; Perez, D.; White, E. Lamin proteolysis facilitates nuclear events during apoptosis. J. Cell Biol. 1996, 135, 1441-1455, doi:10.1083/jcb.135.6.1441.

169. Lenain, C.; Gusyatiner, O.; Douma, S.; van den Broek, B.; Peeper, D. S. Autophagy-mediated degradation of nuclear envelope proteins during oncogene-induced senescence. Carcinogenesis 2015, 36, 1263-1274, doi:10.1093/carcin/bgv124.

170. Liu, Y.; Drozdov, I.; Shroff, R.; Beltran, L. E.; Shanahan, C. M. Prelamin A accelerates vascular calcification via activation of the DNA damage response and senescence-associated secretory phenotype in vascular smooth muscle cells. Circ. Res. 2013, 112, e99-109, doi:10.1161/CIRCRESAHA.111.300543.

171. Uhler, C.; Shivashankar, G. V. Nuclear mechanopathology and cancer diagnosis. Trends Cancer 2018, 4, 320-331, doi:10.1016/j.trecan.2018.02.009.

172. Harada, T.; Swift, J.; Irianto, J.; Shin, J.-W.; Spinler, K. R.; Athirasala, A.; Diegmiller, R.; Dingal, P. C. D. P.; Ivanovska, I. L.; Discher, D. E. Nuclear lamin stiffness is a barrier to 3D migration, but softness can limit survival. J. Cell Biol. 2014, 204, 669-682, doi:10.1083/jcb.201308029.

173. Shimi, T.; Butin-Israeli, V.; Adam, S. A.; Hamanaka, R. B.; Goldman, A. E.; Lucas, C. A.; Shumaker, D. K.; Kosak, S. T.; Chandel, N. S.; Goldman, R. D. The role of nuclear lamin B1 in cell proliferation and senescence. Genes Dev. 2011, 25, 2579-2593, doi:10.1101/gad.179515.111.

174. Saarinen, I.; Mirtti, T.; Seikkula, H.; Boström, P. J.; Taimen, P. Differential Predictive Roles of A- and B-Type Nuclear Lamins in Prostate Cancer Progression. PLoS ONE 2015, 10, e0140671, doi:10.1371/journal.pone.0140671. 
175. Wazir, U.; Ahmed, M. H.; Bridger, J. M.; Harvey, A.; Jiang, W. G.; Sharma, A. K.; Mokbel, K. The clinicopathological significance of lamin A/C, lamin B1 and lamin B receptor mRNA expression in human breast cancer. Cell. Mol. Biol. Lett. 2013, 18, 595-611, doi:10.2478/s11658-013-0109-9.

176. Wu, Z.; Wu, L.; Weng, D.; Xu, D.; Geng, J.; Zhao, F. Reduced expression of lamin A/C correlates with poor histological differentiation and prognosis in primary gastric carcinoma. J. Exp. Clin. Cancer Res. 2009, 28, 8, doi:10.1186/1756-9966-28-8.

177. Belt, E. J. T.; Fijneman, R. J. A.; van den Berg, E. G.; Bril, H.; Delis-van Diemen, P. M.; Tijssen, M.; van Essen, H. F.; de Lange-de Klerk, E. S. M.; Beliën, J. A. M.; Stockmann, H. B. A. C.; Meijer, S.; Meijer, G. A. Loss of lamin $\mathrm{A} / \mathrm{C}$ expression in stage II and III colon cancer is associated with disease recurrence. Eur. J. Cancer 2011, 47, 1837-1845, doi:10.1016/j.ejca.2011.04.025.

178. Gong, G.; Chen, P.; Li, L.; Tan, H.; Zhou, J.; Zhou, Y.; Yang, X.; Wu, X. Loss of lamin A but not lamin C expression in epithelial ovarian cancer cells is associated with metastasis and poor prognosis. Pathol. Res. Pract. 2015, 211, 175-182, doi:10.1016/j.prp.2014.11.008.

179. Kong, L.; Schäfer, G.; Bu, H.; Zhang, Y.; Zhang, Y.; Klocker, H. Lamin A/C protein is overexpressed in tissue-invading prostate cancer and promotes prostate cancer cell growth, migration and invasion through the PI3K/AKT/PTEN pathway. Carcinogenesis 2012, 33, 751-759, doi:10.1093/carcin/bgs022.

180. Willis, N. D.; Wilson, R. G.; Hutchison, C. J. Lamin A: a putative colonic epithelial stem cell biomarker which identifies colorectal tumours with a more aggressive phenotype. Biochem. Soc. Trans. 2008, 36, 13501353, doi:10.1042/BST0361350.

181. Klymenko, T.; Bloehdorn, J.; Bahlo, J.; Robrecht, S.; Akylzhanova, G.; Cox, K.; Estenfelder, S.; Wang, J.; Edelmann, J.; Strefford, J. C.; Wojdacz, T. K.; Fischer, K.; Hallek, M.; Stilgenbauer, S.; Cragg, M.; Gribben, J.; Braun, A. Lamin B1 regulates somatic mutations and progression of B-cell malignancies. Leukemia 2018, 32, 364-375, doi:10.1038/leu.2017.255.

182. Zhang, M.-Y.; Han, Y.-C.; Han, Q.; Liang, Y.; Luo, Y.; Wei, L.; Yan, T.; Yang, Y.; Liu, S.-L.; Wang, E.-H. Lamin B2 promotes the malignant phenotype of non-small cell lung cancer cells by upregulating dimethylation of histone 3 lysine 9. Exp. Cell Res. 2020, 112090, doi:10.1016/j.yexcr.2020.112090.

183. Kent, W. J.; Sugnet, C. W.; Furey, T. S.; Roskin, K. M.; Pringle, T. H.; Zahler, A. M.; Haussler, D. The human genome browser at UCSC. Genome Res. 2002, 12, 996-1006, doi:10.1101/gr.229102. 